\title{
School-to-Work Linkages, Educational Mismatches, and Labor Market Outcomes
}

\author{
Thijs Bol (University of Amsterdam, t.bol@uva.nl) \\ Christina M. Ciocca Eller (Columbia University, cmc2304@columbia.edu) \\ Herman G. van de Werfhorst (University of Amsterdam, h.g.vandewerfhorst@uva.nl) \\ Thomas A. DiPrete (Columbia University, tad61@columbia.edu)
}

Forthcoming in American Sociological Review.

Direct correspondence to: Thijs Bol (t.bol@uva.nl), Department of Sociology, University of Amsterdam, 1000 GG Amsterdam, The Netherlands. The research in this paper has been supported in part by National Science Foundation grant SES-1423828, in part by a Veni grant from the Netherlands' Organization for Scientific Research (NWO) (451-15-001), and in part by a Vici grant from the NWO (453-14-017). The authors want to thank Benjamin Elbers, Luciana de Souza Leão, and the reviewers for their helpful comments. This article has been presented at the RC28 Conferences in Tilburg (2015) and Frankfurt (2019), and seminars at Tilburg University (2017), Harvard University (2018), UT Austin (2018), Chicago University (2018), and the Humboldt University in Berlin (2018). We want to thank all participants to these presentations for their useful comments. Replication code is available at https://osf.io/y2ta9/. This version is from March 6, 2019.

Keywords: Fields of study, labor markets, unemployment, educational attainment, vocational education 


\begin{abstract}
A recurring question in public and scientific debates is whether occupationspecific skills enhance labor market outcomes. Is it beneficial to have an educational degree that is linked to only one or a small set of occupations? To answer this question, we generalize existing models of the effects of (mis)match between education and occupation on labor market outcomes. Specifically, we incorporate the structural effects of linkage strength between school and work, which vary considerably across industrialized countries. In an analysis of France, Germany, and the United States, we find that workers have higher earnings when they are in occupations that match their educational level and field of study, but the size of this earnings boost depends on the clarity and strength of the pathway between their educational credential and the labor market. The earnings premium associated with a good occupational match is larger in countries where the credential has a stronger link to the labor market, but the penalty for a mismatch is also greater in such countries. Moreover, strong linkage reduces unemployment risk. These findings add nuance to often-made arguments that countries with loosely structured educational systems have more flexible labor markets and produce better labor market outcomes for workers. An institutional environment that promotes strong school-to-work pathways appears to be an effective strategy for providing workers with secure, well-paying jobs.
\end{abstract}




\section{Introduction}

In many industrialized countries today, an ongoing challenge is to broaden the proportion of the workforce in well-paying jobs. Both scholars and policymakers view increased education and training as a necessary response to increasing skill demand arising from technological change, and an important strategy for maintaining middleclass wages and combating growing inequality. For instance, Goldin and Katz (2009) argue that the failure of the U.S. educational system to increase educational attainment is one of the most important reasons for rising earnings inequality in the United States since the 1970s. However, a growing literature recognizes that educational performance cannot be measured in terms of years of educational attainment exclusively. Only recently have scholars paid serious attention to field of study or the more fundamental question of how and why field of study matters for occupational attainment, earnings returns, unemployment risk, and the structure of earnings inequality. A relatively small but growing literature attempts to understand the employment and earnings effects of educational level and field of study. This work typically takes a relational perspective, assuming the value of educational credentials depends on the quality of the match between workers' education or training and the job or occupation in which they work (Witte and Kalleberg 1995; Van de Werfhorst 2002; Wolbers 2003; Roksa and Levey 2010). This approach raises an important question that has theoretical and empirical implications: What is the most effective way to create matches between the education system and the labor market?

The answer lies in the institutional structure of national educational systems. A strong tradition in sociology and political science addresses institutional differences in the structure of such systems (Shavit and Müller 1998; Iversen and Soskice 2001). However, these studies generally treat educational and labor market institutions as country-level variables and fail to address within-country heterogeneity of pathways. As a result, they overlook two important issues: first, educational credentials within the same country can be institutionalized quite differently, and second, country differences in the institutionalization of pathways can vary substantially depending on specific educational credentials. These omissions are consequential because institutionalization of pathways between school and work can play as central a role in linking credentials to jobs and in shaping their economic value in the labor market. This article overcomes the limitation of overly broad conceptualizations of structure and demonstrates the value of institutional approaches treating the relational character of education and the labor market at both a structural and an individual level.

We evaluate how the strength of school-to-work pathways shapes the wage and employment effects of (mis)matches between educational outcomes and occupational positions in France, Germany, and the United States. In doing so, we advance existing match quality arguments (e.g., Duncan and Hoffman 1981; Handel 2003; Leuven and Oosterbeek 2011a; Witte and Kalleberg 1995; Van de Werfhorst 2002; Wolbers 2003; Robst 2007) by embedding them in an institutional perspective. We refer to the linkage strength of a country's pathways from specific educational levels and fields of study to specific occupations as the "granular structure" of a country's skill-formation system. This relational, granular perspective improves on the comparative educational literature in sociology (Maurice et al. 1986; Allmendinger 1989; Kerckhoff 1996; Shavit and Müller 1998) and the comparative political economy literature (Hall and Soskice 2001; Iversen and Soskice 2001), both of which focus on the macro-structural characteristics 
of education and training systems articulated at the level of nation-states.

We argue that the extent to which "making a match" pays off in the labor market depends on the structural characteristics of (1) the educational credential and (2) the country. Educational credentials vary in the extent to which they have a strong link to the occupational structure, and this variation itself differs across countries (DiPrete et al. 2017). For some educational qualifications, graduates are likely to end up in the same or very similar occupations (e.g., graduates from medicine); for other educational credentials, the match is less strong (e.g., graduates from social science fields). The linkage strength between credentials and occupations can thus be viewed as a structural characteristic of the educational system influencing the labor market consequences of educational (mis)matches for individual workers.

We also propose that the structure of linkages at the national level influences the extent to which educational (mis)matches affect labor market outcomes. In some countries, the educational system is highly vocational, and graduates are matched to a small set of occupations (Shavit and Müller 1998). Other countries provide students with more general degrees, and workers are expected to be mobile across different labor market segments instead of following a particular pathway from school to work. These structural differences likely affect the returns associated with matching, raising them in countries where the educational system better allocates workers to specific positions in the occupational structure.

Linkage strength between educational outcomes and occupational positions should also affect the risk of unemployment. Sociologists who study comparative educational systems have argued that workers in countries with strong vocational systems have reduced unemployment risk early in their careers (Breen 2005). We expect this to hold even more strongly when considering the context of specific pathways, rather than the country as a whole, as the contextual unit of analysis.

We test our hypotheses by using a novel analytic strategy based on multigroup segregation theory to define the strength of linkages between specific educational qualifications and the occupational structure (DiPrete et al. 2017). We then examine whether and how the effects on wages of making a (mis)match between education and occupation depend on the linkage strength of educational qualifications and whether the effects of linkage strength vary by the national context. Finally, we study the extent to which the effects vary by gender, over the life course, and in regard to unemployment. In doing so, we reevaluate findings from existing research showing workers from countries with strong vocational educational systems lack the flexible training to adjust to changing technology and are therefore at higher risk for unemployment later in their careers (Hanushek et al. 2017; Forster et al. 2016). We do so through our theoretical framework that uses the linkage strength of educational credentials rather than the country as a whole as the unit of structure.

Our analyses use microdata for France, Germany, and the United States, three countries that vary greatly in the extent to which their educational systems are vocationally specific and match workers with specific educational credentials to specific occupations (Shavit and Müller 1998; Bol and Van de Werfhorst 2013). We analyze how individuallevel effects of making a match depend on a qualification's linkage strength. With our regression analyses, we first explain within-country variance in earnings by determining the extent of returns to matched and unmatched workers with more strongly linked educational qualifications in the three countries (e.g., Roksa and Levey 2010; Wolbers 2003; Van de Werfhorst 2002). This design also allows us to compare results across the 
three countries, shedding light on cross-national differences.

To relax the strong assumption of the within-country design - that all relevant differences across educational fields are controlled for - our second design uses fixed effects for educational qualifications in a three-country analysis. In this design, we use crossnational variation in linkage strength of the same educational qualifications to identify the implications of differences in linkage strength.

Generally, the two modeling strategies produce consistent results about the effects of linkage strength on labor market outcomes: more strongly linking educational qualifications are associated with higher earnings, but especially so for workers who make the match, and especially in countries where the educational system is highly occupationally specific.

\section{Theoretical background}

\section{Educational (mis)matches, linkage strength, and labor market out- comes}

A long-standing literature in sociology on skill match and mismatch traces back to often conflicting theories of the social consequences of automation, credentialism, deskilling, and the emergence of a post-industrial society (Handel 2003).In microeconomics, most existing work on skill mismatch focuses on the consequences of the baby-boomer-fueled increase in the supply of higher education in the 1970s. First, the increased supply drove down returns to higher education (Freeman 1976); second, it led to increased "overeducation" relative to the requirements for one's job (Duncan and Hoffman 1981). "Overeducation" and "undereducation" collectively came to be known in the economics literature as skill "mismatch" (Leuven and Oosterbeek 2011b). Several studies find that in a vertical mismatch-workers having higher or lower education than the level required for their current job-individuals receive a reduced reward for mismatched schooling compared with required schooling (McGuinness 2006; Korpi and Tåhlin 2009; Nordin et al. 2010). In a similar vein, Pedulla (2016) finds a strong scarring effect of a mismatch: workers with a history of having higher credentials than required in previous jobs require suffer a penalty in the labor market.

More recently, the economics literature (e.g., Robst 2007; Béduwé and Giret 2011; Levels et al. 2014; Montt 2015; Kirkeboen et al. 2016) has begun to draw on earlier work by sociologists on horizontal mismatches (Witte and Kalleberg 1995; Van de Werfhorst 2002; Wolbers 2003), studying whether workers are employed in jobs corresponding to their field of study, and what the labor market effects of such horizontal (mis)matches are. Studies of (horizontal and vertical) skill mismatch can be categorized according to whether scholars have used objective or worker self-reports of (mis)match. Here, "objective" typically means the analyst has coded (mis)match based on the analyst's or other expert's evaluation of the relationship between a worker's educational credential and an occupation, rather than relying on respondents' self-reported associations between educational credentials and occupations.

Using such objective measures, Van de Werfhorst (2002) shows that a good match between field of study and the labor market in the Netherlands is positively associated with wages. Wolbers (2003) has similar findings for early-career workers across Europe: individuals with a match attain jobs with higher occupational status, especially in countries having less vocationally-oriented educational systems. Béduwé and Giret 
(2011) examine rates and consequences of horizontal mismatch in France, finding very high rates of mismatch for vocationally trained workers and evidence of a vertical mismatch, but only small effects of horizontal mismatch after other job characteristics are taken into account. Finally, Montt (2015) finds that rates of mismatch vary with national-level measures of supply and demand, and mismatched workers suffer wage penalties - especially if mismatch stems from jobs that require lower levels of education than workers possess.

Using self-reported measures of (mis)match, Witte and Kalleberg (1995) find that fit between workers' field of educational degree and their occupation declines with age in Germany. In addition, Robst (2007) finds that rates of self-reported mismatch are high (nearly 50 percent), mismatch grows with age, and mismatch appears to be greater for fields that - in his view - impart more general than occupation-specific skills in his study of the United States. Robst also reports that mismatch is associated with lower earnings.

The general message from this literature is that individuals with a good educationoccupation match earn, on average, higher wages than mismatched workers with similar education. Most studies rely on human capital theory (Becker 1962) to explain this positive association. The key argument is that individuals learn occupation-specific skills in school, and those with the right match will be able to translate these skills into productivity and wages. That said, a long-standing tradition within sociology emphasizes the credentialing and sorting process over the skill-production aspects of education and training (Bourdieu 1973; Collins 1979; Labaree 1999; Domina et al. 2017)). This tradition generally sees education as a status-reproducing rather than a mobility-enhancing institution, where credentialing is a sorting process connected to status-maintenance rather than driven by skill acquisition. Credentialing theory argues that status competition leads to overeducation, but it does not have much to say about field of study and horizontal mismatch effects.

Our approach is related to this (mis)match literature, but it differs and improves on its theoretical and empirical dimensions in important ways. First, we conceptualize (mis)match as both vertical and horizontal. The concept of mismatch is an individuallevel construct defined primarily in terms of whether workers have the right "level or field" of education for their jobs. Our approach, in contrast, focuses on the structural aspects that might affect the likelihood and labor market effects of making a match, and thereby goes beyond the somewhat artificial distinction between vertical and horizontal mismatches. Such a distinction would uncomfortably suggest, for instance, that medical doctors could be vertically mismatched but horizontally matched if they took a job as a nurse. It is more useful to see the (limited) set of occupations in which graduates with a medical degree enroll to determine whether the educational credential is strongly matched to the labor market. In addition, and in contrast to existing literature, we focus not only on cross-national variation in structural conditions (Montt 2015; Verhaest and Van der Velden 2013), but we hypothesize that within- and between-country variation in the strength of pathways between educational qualifications and specific occupations play a role as well. In other words, school-to-work transitions depend not only on workers' characteristics, and not only on macro-structural conditions, but also on the linkage strength of particular educational pathways.

Second, we take an objective approach to the measurement of individual-level (mis)matches consistent with our data-driven use of entropy-based segregation to measure linkage strength (as discussed below). At the structural level, high linkage cor- 
responds with high predictability of occupational destinations, conditional on the educational credential. A matching occupation is one where the association between educational field and occupation is high for workers with any specified level of education. Accordingly, workers are defined as making a match when they are employed in an occupation that is common for graduates with the same educational credential.

Our approach to (mis)matches can thus be distinguished from previous "objective" approaches to identifying matches (e.g., an investigator who decides that graduates of tertiary engineering programs are "matched" when they work in engineering occupations, as in Wolbers 2003 or Katz-Gerro and Yaish 2003). It is also different from the use of subjective self-reports in which workers evaluate the utilization of skills from their education in their current occupation (Witte and Kalleberg 1995; Robst 2007). Aside from its consistency with our structural measures, our approach avoids the problems with coding reliability that stem from different decisions made by different investigators. It also avoids the problems of using respondent-driven subjective assessments, which might be applied differently in different national contexts. ${ }^{1}$

\section{Cross-national differences}

In the past few years, the matching literature in economics has developed a comparative stream, examining whether cross-national variation in the supply and demand of university graduates affects the rate of overeducation (e.g., Croce and Ghignoni 2012; Ghignoni and Verashchagina 2014). In sociology, an important line of comparative research has been optimistic about the consequences of strong vocational education and training (VET) systems that have a strong focus on occupation-specific skills. According to this literature, movement from the educational system to the labor market typically runs more smoothly in systems with a strong VET sector, such as Germany, Switzerland, or the Netherlands (Shavit and Müller 1998; Müller and Gangl 2003). Indeed, studies find lower youth-to-adult unemployment rates(Breen 2005), higher entry rates into skilled trades among school leavers with medium-level qualifications (Müller and Shavit 1998), and a more limited tendency for credential inflation without corresponding labor market benefits (e.g., Aizenman et al. 2017). Comparative studies also show that the "quality" of employment in terms of occupational status and stable careers is more strongly related to educational qualifications in countries with welldeveloped VET systems (Gangl 2004; Wolbers 2007).

Following this literature, we argue that in countries with strong occupation-specific educational systems, there are relatively large benefits for graduates who work in occupations that are a good match to their educational credentials. At the same time, we also expect a relatively large penalty for graduates who fail to make the expected match in these countries. This pattern contrasts with countries where the educational system is more general in the skills it provides and the occupational pathways it paves for graduates. In such countries, we hypothesize that the benefits for matching will be smaller, but so will the penalties for not matching. Di Stasio (2017) provides some support for this reasoning, finding that a mismatch is more strongly penalized by Dutch than by English employers.

To test this macro-level theory, we conduct an analysis of three countries: Germany, the United States, and France. The three countries have very different skill-formation

\footnotetext{
${ }^{1}$ Our method also allows the use of large national datasets for measuring linkage and (mis)matches even when subjective assessment questions are not available.
} 
systems, particularly with regard to occupationally specific learning (Bol and Van de Werfhorst 2013; DiPrete et al. 2017).

The German system is most strongly occupationally specific: it has a large apprenticeship system catering to students in many different educational careers as well as school-based vocational education (BMBF 2015). The German system selects students early (age 10 or 12) into either gymnasium, which prepares them for the university entrance exam Abitur, or lower-level tracks, which prepare students for apprenticeships. This system creates stratification between the VET system and the general education system leading to university. However, a sizable group of graduates from the gymnasium enters apprenticeships instead of going to higher education, so there is also stratification within the VET system (Protsch and Solga 2016). Vocational qualifications in both the work-based dual system and the school-based system lead to fully recognized certificates. Germany also has an occupationally-specific higher education sector, which exists alongside regular research-oriented universities. Earlier studies have found that the pathways from school to work are comparatively strong in Germany even at the university level (Leuze 2007).

The German VET system developed in a political economy in which specific skills were provided by the education system in conjunction with strong employment protection legislation. The goal of such legislation was to increase students' willingness to invest in specific skills, but it in turn has reduced students' options in the labor market (Iversen and Soskice 2001). The German system has successfully adjusted to changing economic circumstances through intense consultation and negotiation between employer organizations, trade unions, the German Lander, and the German federal state, including during periods when the VET systems of other countries were under threat (Thelen 2004).

The U.S. educational system is, in many ways, the opposite of the German system. Vocational training is much less well developed, is not nationally standardized, and involves less collaboration with employers. American VET typically does not prepare students for certificates that are fully recognized as job requirements in the U.S. labor market. In the language of the political economy literature, the United States is a model for a different "skill equilibrium" (Iversen and Soskice 2001), with a more generically oriented educational system and little employment protection. We expect a greater dispersion of American VET graduates across the occupational structure than is true in Germany, although there is likely much variation within both countries.

The French educational system falls somewhat in between the extremes of Germany and the United States. France has a sizable vocational and technical baccalauréat that students can enter after college, but it is not as collaborative with employers as in Germany. Unlike the German system, there are hardly any dual forms of VET. Although more occupationally specific than academically oriented forms of secondary education exist, these vocational and technical programs are firmly rooted in schoolbased learning environments and encompassed by the French baccalauréat system.

We hypothesize that countries exert important structural effects that influence labor market returns to educational matches. At the same time, the categorization of Germany as being vocational and the United States as being general is overly simplistic (DiPrete et al. 2017); it fails to sufficiently appreciate that educational programs can differ in the linkage strength of their pathways to specific occupations within a given country. Even when educational programs sound equally "occupational" in their content, they can differ in their labor market consequences, either because supply is 
not clearly linked to demand, or because schools have not convinced employers of the value of their programs. Moreover, despite cross-national differences in educational institutional structure, there are also possible similarities across the three countries in the matching process of educational qualifications to occupations and the associated wage returns, which will become apparent with our granular approach to matching. One example is the field of health, which is strongly linked to the labor market in all three countries, although it is yet unknown to what extent the wage return to matching in this field varies across societies.

The existing literature focuses either on educational systems or on occupations as the empirical basis for reaching conclusions about the value of competing systems, and it often relies on rather coarse characterizations of national systems in the comparative research designs. We argue, in contrast, that within-country differences in the linkage strength of educational qualifications are crucial to understanding how educational matches affect labor market returns.

\section{Linkage strength}

Recent scholarship shows different levels of attachment of educational qualifications to occupational destinations, both between and within national educational systems (Allen et al. 2000; Vogtenhuber 2014; DiPrete et al. 2017; Forster and Bol 2018). DiPrete et al. (2017) find substantial heterogeneity in the strength of linkage between educational outcomes and the occupational distribution at the same educational level in the same country. They also find substantial differences in the aggregate level and distribution of linkage strength across countries. One important finding is that the binary classification of national educational systems as vocational versus general is ill-suited to measure the labor market effects of educational qualifications. Some qualifications in traditional universities, for instance, are highly occupationally specific (e.g., engineering and health), whereas some programs in vocational schools are much more general in terms of the wide variety of occupations where graduates land (e.g., business).

How might linkage strength affect labor market outcomes? Workers with a stronger school-to-work pathway will have more specific skills that can be used immediately. Graduates from educational fields with a strong linkage to a (limited set of) specific occupation(s) will be more productive, which should be reflected in their earnings and unemployment risk. However, the labor market advantages associated with having a clear occupational pathway will only be available to those who follow that pathway: having plumbing skills when one ends up in an accounting job is unlikely to increase productivity and thereby labor market returns. In other words, human capital theory expects the returns to specific skills to be highest for those who actually make the match: someone with a plumbing degree who ends up working as a plumber. Credentialism theory would also predict this to be the case, be it for reasons other than (only) skill use. In credentialized settings, where formal or informal rules govern access to occupations, a credential only becomes valuable when it is deployed in occupations where it is used as a sorting device (Collins 1979).

Our proposition is therefore that the linkage strength of the educational credential affects the extent to which making a match results in an earnings premium. In a context where graduates are clearly schooled for one or a few occupations (e.g., a plumbing degree), graduates who make the match will reap the benefits from the occupationspecific skills they acquired. Conversely, graduates who do not make the match will 
generally receive lower wages: they have obtained a set of specific skills they cannot put to use. The wages of graduates with more general qualifications that do not link very strongly will be much less affected by their (mis)match. Their general set of skills allows them to be mobile across different occupations in the labor market.

A second mechanism supporting our proposition is derived from the occupational closure literature (Weeden 2002; Kleiner 2006; Bol and Weeden 2015; Redbird 2017). Here the strong linkage between educational qualifications and occupations would not just signal a high level of skill-specificity, but would also indicate the potential presence of institutions regulating access to occupations. To obtain a medical license, a prerequisite is to have a medical degree; to become a self-employed licensed scaffolder in Germany, one needs a specific vocational degree that gives access to the occupation (Bol 2014). Similarly, the wage premium associated with occupational closure should only be reaped by those working in the "closed" occupation.

\section{Summary and hypotheses}

According to the matching literature, education has a rate of return, and that rate of return is heightened when a worker is in a job using that education. From this perspective, matching is an individual-level condition. Well-organized occupational pathways influence the rate at which matching occurs, but the entire effect of linkage flows through the individual condition of being well or poorly matched.

Theoretical and practical objections can be raised to such an individualized approach. At the theoretical level, the value of a particular educational credential may well depend on its institutional character as well as the specific skills it imparts. First, an educational qualification with a clear connection to specific occupations may do a better job of signaling to the market the "value" of that field. Second, a more appropriately trained workforce may allow employers to adopt technologies that, in combination with trained labor, are more productive. Third, individuals who hold credentials in fields with strong labor market linkage may have greater power to extract higher pay in the market via unions or occupational associations (Weeden 2002).

At a practical level, individual-level matching is often hard to measure because specific educational programs impart many skills and specific occupations use many skills. A "match," in other words, is neither a binary nor a unidimensional property of the relationship between a specific educational outcome and a specific occupation. To the extent that pathways between educational programs and the labor market are well structured, it becomes more likely that graduates from such programs are employed in occupations that make use of their skills. In short, graduates of a strongly linked educational program arguably have a higher probability of being located in a suitable occupation even net of individual-level measures of whether their occupation is a good match for their skills. Structural linkage, in other words, may be a good indicator for match quality even net of individual measures of job "match."

Our first hypothesis is that workers whose occupations match well to their educational qualifications will generally earn more than workers who have the same qualification but are in a different occupation (Hypothesis 1). This expectation follows naturally from the presumption that workers who are well matched can make better use of their skills in their jobs and will generally be rewarded for this.

Our second hypothesis is that labor market returns to educational qualifications will depend on the structure of linkage, and specifically on the linkage strength of 
an educational credential. In general, we hypothesize that stronger linkage increases returns to an educational qualification (Hypothesis 2). We expect that strong linkage enhances employers' ability to structure work to make even more productive use of workers with the best educational fit to the occupation. We also expect strong linkage to produce institutionally-based effects on earnings (e.g., via closure mechanisms) that benefit workers in occupations that more strongly link to educational qualifications.

At the same time, we expect the benefits of strong linkage to accrue primarily to workers who are in occupations that match their educational qualifications (Hypothesis 3). This implies an interaction between the individual-level characteristic of being (mis)matched and the structural characteristic of the linkage strength of educational credentials. Based on human capital and closure arguments, we expect the benefits of strong linkage primarily exist for individuals who work in jobs that strongly match their education.

Finally, we argue that the structure of linkages at the national level matters as well. Especially in countries with a strong occupation-specific education system, the benefits to making the match (or the penalty to not making the match) will be large (Hypothesis 4). For the three countries we analyze, this means the largest wage returns to making a match should be in Germany, followed by France, and then the United States. German graduates are more likely to follow clear occupational pathways, and they will lose out on labor market returns if they do not do so. Because of strong licensing requirements in Germany's credential-based system, we expect mismatched workers will end up in worse jobs than they would if the barriers to occupational entry were lower. American workers might also benefit from following educational pathways that link closely with occupations, but they might suffer less if they fail to do so. In the United States, the barriers to entering good occupations that are not direct matches to one's educational credentials are arguably not as high as in a credential-based system such as Germany. For example, it is easier for U.S. employers to hire someone into a good job with the "wrong" education because they think the worker has other pertinent skills or talents.

Following the earnings analyses, we address the question of how the structure of linkage affects employment outcomes. Scholars have argued both sides of this question: different theories make different predictions about whether strongly linked educational systems are generally superior to weakly linked systems or whether they involve important tradeoffs between immediate job prospects and longer-term flexibility. We treat this issue as an empirical question of great importance and use our analytic strategy to provide an answer.

\section{Analytical Strategy and Data Description}

\section{Data}

For France, we use the Enquête Emploi, a quarterly labor force survey of 60,000 to 80,000 household members. Like most European labor force surveys, the Enquête Emploi uses a rotating panel format, with respondents participating in six quarters. To avoid duplicate observations for the same respondents, we use only the observation from the first quarter in which a respondent participated for the years 2005 to 2011. The analytic sample size for France is 102,292.

The German analyses use the 2006 Mikrozensus (Microcensus), a random sample of roughly 1 percent of German households. All household members age at least 15 are 
interviewed. The analytic sample size for Germany is 108,025.

Data for the United States are based on a combination of the 2009 American Community Survey (ACS) and the Survey of Income and Program Participation (SIPP) for 2004 and 2008. ${ }^{2}$ The ACS is a large survey, containing roughly 1 percent of the U.S. population, but it does not contain information on field of study for lower tertiary educational credentials or postgraduate degrees. The SIPP data provide more detailed information on educational fields. We reweight the SIPP data to make the weights comparable to the ACS weights, and we then combine these two datasets to obtain coverage on fields of study at the community college, four-year college, and graduate levels. The analytic sample size for the United States is 223,517 , but this number excludes high school graduates, who in the U.S. educational system do not graduate with specific fields of study.

For all three countries, our main analyses are performed on an analytic sample consisting of employed persons who work full-time and are between the ages of 18 and 65 . We exclude the self-employed from the earnings analyses because earnings for self-employed workers are not reported in the French data. The main analyses focus only on full-time workers because we have limited information on the working hours of respondents who are not full-time in the German and U.S. data. This lack of workinghours information makes it difficult to interpret the meaning of earnings analyses for part-time workers, that is, we cannot distinguish the earnings from the hours effects on total earnings for part-time workers. However, as a robustness check we analyzed earnings results for part-time workers and we obtained similar results (see the online supplement). For the analyses where unemployment is the dependent variable, we include all part-time and full-time wage and salary workers along with self-employed workers and the unemployed (sample sizes for this analysis are listed in Appendix Table refa1).

Missing data on the independent variables is only a minor concern. Earnings information is missing for about 10,000 workers in the German data and about 100 workers in the U.S. data. ${ }^{3}$ Details on how the samples were constructed can be found in Appendix Table A2.

\section{Dependent variables: Earnings and Unemployment}

The first dependent variable of interest is gross monthly earnings for sample members who work full-time. In the French data, this variable is directly available for all wage and salary workers in the labor force surveys. ${ }^{4}$ MMonthly earnings are also directly available in the SIPP. We create a comparable measure from the ACS data by dividing the "yearly earnings" variable by 12.5 In the German Microcensus, we only have

\footnotetext{
${ }^{2}$ We do not use the 2014 SIPP because only the first wave is currently available, and this wave does not include the field of study module, which is necessary to estimate linkage strength.

${ }^{3}$ The U.S. ACS data also include earnings information for 51,271 individuals who self-classify as "not in the labor force." These earnings are available because the ACS asks respondents to report earnings from the previous 12 months. However, to remain in our sample, respondents must be working currently, so we dropped all individuals who reported they were not in the labor force as of the survey date.

${ }^{4}$ Earnings are unavailable for self-employed workers in France, and thus we exclude the self-employed from our analytic sample when earnings are the dependent variable.

${ }^{5}$ In both the SIPP and the ACS, respondents are asked to provide their total earnings during the focal period of time rather than earnings in relation to one specific job or occupation. It is therefore possible that respondents gained earnings from multiple occupations. However, in both surveys, respondents
} 
information on respondents' monthly income along with a measure of whether their main source of income was from labor. To improve comparability across countries, we use data from the German Socio-Economic Panel (SOEP), which contains information on monthly personal income and monthly labor earnings, to predict earnings from personal income. ${ }^{6}$ We use the prediction equation for earnings from this model, which is able to explain 95 percent of the variance in gross earnings in the SOEP, to impute earnings from personal income. For the sake of comparability, we rescaled the French and Germany earnings to 2009 U.S. dollars.

The second dependent variable we study is unemployment. Unemployment is a binary variable, indicating if individuals are unemployed (1) or employed (0) as of the reference period in the survey. Individuals who are inactive, are still in school, have a disability, or are on a pension are excluded from these analyses. For the analyses of unemployment, we include all workers (part-time and full-time, self-employed, and employees).

\section{Linkage Strength}

We measure the linkage strength of educational credentials following DiPrete et al. (2017), who use multigroup segregation measures to indicate the extent to which workers with the same educational credential (expressed in level and in field) are clustered in a set of occupations. Their approach is based on the Mutual Information Index $(M) . M$ has the important benefit of being decomposable in theoretically useful ways (Mora and Ruiz-Castillo 2011; Mora and Ruiz-Castillo Ucelay 2009). Specifically, the total $M$ can be decomposed into what DiPrete et al. (2017) call "linkage" scores for every educational outcome, where the linkage score for education categories takes the following form:

$$
M(e d)_{g}=\sum_{j} p_{j \mid g} \log \left(\frac{p_{j \mid g}}{p_{j}}\right)
$$

In equation (1), $p_{j \mid g}$ is the conditional probability of working in occupation $j$ given that one is in educational outcome $g$, and $p_{j}$ is the unconditional probability of working in occupation $j$. The linkage strength thus indicates the extent to which workers with a a shared educational background are clustered in a relatively small number of occupations. ${ }^{7}$ If graduates are clustered in only a small number of occupations, the linkage score will be high. DiPrete et al. (2017) fithat medicine has a much higher linkage score than does a tertiary degree in the humanities. This means a higher proportion of graduates with a medical degree work in the one or two most common occupational destinations for graduates with medical degrees than is the case for tertiary graduates with humanities as their field of study.

In our study, education is always measured as a combination of educational level and field of study. For the calculation of linkage strength, we create unique combinations

are also asked to identify their "primary" occupation, or the occupation in which they have worked the most hours. We use the primary occupation when computing measures of linkage and whether the worker is in a matched occupation.

${ }^{6}$ The prediction model also includes interactions between income and age and between income and household status.

${ }^{7} M$ can equivalently be decomposed into the weighted sum of linkage strengths for each of the occupations constituting some occupational scheme. For purposes of the present paper, we focus attention on $M(e d)_{g}$ rather than $M(o c c)_{j}$. 
of levels and fields $(g)$, and calculate how they are linked to occupations $(j)$. We measure educational level using the ISCED-97 classification (see Appendix Table A3 for a description of the codes). We focus on graduates from upper-secondary education and higher levels for the French and German analyses, because these are the levels that have variation in educational fields. This means we distinguish between $3 \mathrm{C}, 3 \mathrm{~B}, 3 \mathrm{~A}$, 4, 5B, 5A, 6B, and 6A. Analyses are separated by secondary degrees (up to ISCED 4) and tertiary degrees (5A and higher). For analyses including the U.S. data, we focus only on lower- and upper-tertiary educational levels because these are the levels that have variation by educational field in the U.S. system.

We harmonize fields of study within levels of education using the two-digit ISCED classification, which distinguishes a maximum of 24 fields within levels (see Appendix Table A4). Our coding system includes an "other" code for respondents who hold a field of study that was not classifiable into one of the 24 explicit fields. A very small fraction of respondents had a missing field; we dropped these cases from the analysis.

By using all unique combinations of educational levels and fields (g), our analytic sample contains 66 categories of educational levels and fields for France, 82 for Germany, and 53 for the United States. We only keep educational level and field combinations with a minimum of 100 observations. Using categories with fewer than 100 observations might lead to sparseness bias: segregation will appear to be greater in samples with relatively few members in a given educational level and field. Using lower thresholds, however, does not affect our main findings (see the online supplement).

We measure occupational destinations ( $\mathrm{j}$ ) using three-digit ISCO-88 codes for crossnational comparisons because it is the international standard and, by EU regulations, is already coded into the German and French data by the national statistical agencies. We converted U.S. Census 2000 codes into ISCO-88 codes using an existing crosswalk (Elliott and Gerova 2005). We harmonized the ISCO-88 three-digit groups so the same 90 occupational categories are used in all three countries. This means we merge some small or nonexistent occupations together: rubber- and plastic-products machine operators (ISCO-88 category 823), for example, are merged with wood-products machine operators (category 824).

\section{Matched Occupation}

In the earnings regressions, we also measure whether each employed individual works in an occupation that strongly links to their educational credential. We call such an occupation a "matched" occupation. Employment in a matched occupation is operationalized as the extent to which one is more likely to be working in an occupation given one's educational level and field than would be the case if one's occupation was statistically independent of one's educational field, conditional on one's educational level. We then compare these counterfactual frequencies with the actual frequencies. The ratio of these two quantities is a measure of how strongly associated any particular educational field is with each occupation for workers with that given level of education.

First, we identify the 10 largest occupational destinations (using the harmonized three-digit ISCO-88 classification) for each combination of level and field. The largest occupational destinations are a natural search space for "best-matching" occupations, but some occupations may fall within this group of 10 simply because they contain a relatively large share of the total work force. We therefore take the additional step of comparing the number of occupational incumbents with the number that would 
be expected if field of study was unrelated to occupational incumbency, conditional on educational level. We identify the two occupations from the 10 most common occupational destinations where the number of occupational incumbents represents the largest proportional increase over what would be expected if fields were not related to occupations within the specific educational level. ${ }^{8}$ We call them the "matched" occupations. ${ }^{9}$ A list of matched occupations for each level and field combination in our data can be found in the online supplement. ${ }^{10}$ As expected, the probability of being in a matched occupation is considerably higher for workers whose credential has a stronger linkage strength. However, it is important to remember that linkage strength and being in a matched occupation are measured at two different levels: the first is a characteristic of an educational credential, the second is a characteristic of an individual.

\section{Other Variables and Descriptives}

In the analyses of the effects of linkage strength and being in a matched occupation on earnings using data from labor force survey analyses, we control for age and age squared, full-time work, and gender. For some models we perform separate analyses by age (younger versus older workers) and gender. The group of older workers is defined as everyone over 45 years, as Forster et al. (2016) Table 1 provides descriptive statistics of all the variables in our models, listed separately by country. We provide the means and standard deviations of linkage strength separately for secondary and tertiary degreeholders. The descriptive statistics of the sample used for the unemployment analyses can be found in Appendix Table A1.

\section{Model}

As noted earlier, existing literature has found evidence that workers gain wage benefits from matching well to their jobs. Our goal is to make sense of this finding within a structural context. First, we establish whether the strength of linkage between school and work is one of the reasons why some educational fields are more highly rewarded

\footnotetext{
${ }^{8}$ The reason to only take the most common occupational destinations is because otherwise implausible matches are sometimes possible. For example, imagine that only $0.1 \%$ of respondents with a tertiary degree (ISCED 5A) become taxi drivers, but all taxi drivers with a BA degree have majored in social sciences. If we did not restrict attention to the most common occupational destinations for social science tertiary graduates, taxi driver could in this scenario come out as a matched occupation even though very few college graduates in general are taxi drivers and in particular very few social science college graduates are taxi drivers. By restricting attention to the ten largest occupations, we avoid this problem.

${ }^{9}$ Analyses where our measure of being in a matched occupation is based on working in one of the three or four (as opposed to two) occupations with the largest ratio give very similar results. These results can be found in the online supplement.

${ }^{10} \mathrm{An}$ alternative approach to the simultaneous modeling of structural linkage and individual (mis)matches would be to treat matching and mismatching as a continuous variable so that we measured the benefits or penalties that accrue to the quality of the match across various amounts of horizontal and vertical mismatch. Our empirical, data-driven approach to matching has the advantage of actually providing a computable measure of match quality, which is, for example, implausible with a normative approach to the measuring of (mis)match. If a comprehensive measure of degree of mismatch was the goal, it would be reasonable to consider measures based on unconditional (on educational level) expectations under an assumed independence of educational outcome and occupational destination. This approach is beyond the scope of the current article but warrants future investigation.
} 
Table 1: Descriptive Statistics

\begin{tabular}{|c|c|c|c|c|c|c|}
\hline & \multicolumn{2}{|c|}{ France } & \multicolumn{2}{|c|}{ Germany } & \multicolumn{2}{|c|}{ US } \\
\hline & Mean & $\mathrm{SD}$ & Mean & $\mathrm{SD}$ & Mean & $\mathrm{SD}$ \\
\hline Linkage strength & 0.89 & 0.56 & 1.05 & 0.61 & 0.94 & 0.66 \\
\hline Linkage strength (secondary) & 0.64 & 0.33 & 0.82 & 0.41 & - & \\
\hline Linkage strength (tertiary) & 1.25 & 0.61 & 1.55 & 0.68 & 0.94 & 0.66 \\
\hline In matched occ. (secondary) & 0.23 & & 0.23 & & - & \\
\hline In matched occ. (tertiary) & 0.34 & & 0.39 & & 0.29 & \\
\hline \multicolumn{7}{|l|}{ ISCED level } \\
\hline $3 \mathrm{C}$ & 0.37 & & - & & - & \\
\hline $3 \mathrm{~B}$ & 0.06 & & 0.58 & & - & \\
\hline $3 \mathrm{~A}$ & 0.16 & & 0.02 & & - & \\
\hline $4 \mathrm{~A}$ & - & & 0.08 & & - & \\
\hline $5 \mathrm{~B}$ & 0.17 & & 0.11 & & 0.20 & \\
\hline $5 \mathrm{~A}$ & 0.24 & & 0.18 & & 0.51 & \\
\hline $6 \mathrm{~B}$ & - & & - & & 0.20 & \\
\hline $6 \mathrm{~A}$ & 0.01 & & 0.01 & & 0.08 & \\
\hline Age & 38.51 & 10.68 & 41.22 & 10.80 & 42.36 & 11.07 \\
\hline Female & 0.43 & & 0.33 & & 0.46 & \\
\hline ln Monthly wages & 7.62 & 0.45 & 8.06 & 0.52 & 8.41 & 0.74 \\
\hline \multicolumn{7}{|l|}{ Age category } \\
\hline$<45$ years old & 0.68 & & 0.60 & & 0.56 & \\
\hline $45=>$ years old & 0.32 & & 0.40 & & 0.44 & \\
\hline$N$ & 102 & 292 & 108 & 025 & & 517 \\
\hline
\end{tabular}


than others. Second, we determine the extent to which this effect depends on whether individuals are working in an occupation that links well to their educational level and field of study (Hypothesis 3). To identify the effects of the linkage strength of a field on the average earnings in a field, we use two designs, each having different benefits.

In the within-country design, we regress the log of gross monthly earnings on our measure of linkage strength and the variable indicating if individuals are employed in a matched occupation. We control for educational level, so the effects are net of level differences in earnings (e.g., college graduates typically earn more than uppersecondary graduates). We perform this regression for each country separately. This means the counterfactual to a high-linking educational field is a different, weak-linking, educational field in the same country and at the same educational level.

$$
y_{i}=\alpha+\beta_{1} L_{i g}+\beta_{2} M_{i g}+\beta_{3} L_{i g} M_{i g}+\Sigma \gamma_{l} S_{i l}+\delta X_{i}+\varepsilon_{i}
$$

Equation 2 shows the first set of regressions that we employ, where $y$ is the log earnings for full-time worker $i$, and $\beta_{1}$ is the effect of linkage $(L)$ for individual $i$, which is a function of individual $i$ 's level and field combination in level and field combination $g$. $M_{i g}$ is a dummy variable equal to one if individual $i$ is working in a matched occupation for one's educational (level and field) outcome $g$. Its main effect is measured in $\beta_{2}$, and the extent to which returns to making a match depend on the linkage strength of an educational credential is measured by the interaction effect $\beta_{3}$. $S_{i l}$ is a set of dummy variables indicating whether individual $i$ has level of schooling $l$, and $X$ is a vector of other control variables for individual $i$.

One potential problem in accurately interpreting the coefficients from Equation 2 is that the apparent effect of linkage on earnings could be driven by other relevant labor market characteristics of the educational credential that are associated with its linkage strength. Maybe more talented students select into more strongly linking educational programs. Consequently, the coefficient estimates may not consistently measure a causal effect of linkage strength on labor market returns. To mitigate this problem, we use a second design that exploits variation in labor market earnings among workers in the same broad educational level and field in the three countries under study. Instead of modeling the variation in earnings across different fields within the same country, we model earnings differences between the same field across countries. ${ }^{11}$ Using this system, we obtain Equation (3):

$$
y_{i}=\alpha+\beta_{1} L_{i g m}+\beta_{2} M_{i g m}+\beta_{3} L_{i g m} M_{i g m}+\delta X_{i}+\zeta_{j} F_{i j}+\Sigma \gamma_{l} S_{i l}+\varphi C_{i}+\varepsilon_{i}
$$

where $i$ indicates individuals, $j$ indicates broad level-field, $g$ indicates narrow level-field, $l$ indicates ISCED educational level, and $m$ indicates country .Using this notation, $\zeta_{j}$ is the effect of the broad level-field combination using ISCED educational fields and the broad educational level coding described in the above paragraph and $F_{i j}$ is the broad

\footnotetext{
${ }^{11}$ France and Germany differ in the $3 \mathrm{~A} / 3 \mathrm{~B} / 3 \mathrm{C}$ ISCED classification of their secondary-school leaving degrees, with secondary-school French graduates largely being classified at level $3 \mathrm{~A}$ or $3 \mathrm{C}$ and German secondary-school graduates largely being classified at level 3B. For purposes of the betweencountry/within-field analyses, we grouped all fields at levels 3A, 3B, 3C, and 4A into a common "level 3" school outcome while keeping them in their specific fields to create a broad level-field variable. We also collapse $6 \mathrm{~A}$ with $6 \mathrm{~B}$ in the U.S. data in the broad level-field classification to conform with the German and French educational system, where this distinction is not meaningful.
} 
level-field combination $j$ of individual $i . L_{i g m}$ is the linkage score for the narrow levelfield $g$ in country $m, S_{i l}$ is a set of dummy variables indicating whether individual i has educational level $l$ (which can vary within broad level-fields), $C_{i}$ is the country and $X_{i}$ are individual characteristics (gender, age) for individual $i$. This approach represents a fixed-effects specification in the broad level-field categories, and the $\gamma$ coefficients measure the effects of differences in educational level on earnings for workers in the same broad level-field combination. We also adjusted the weights so they apply to the combined French-German-American employed population. This means workers "count" the same toward the regression results regardless of which country they are in.

Our analyses of unemployment follow the same general format, with the exception that we estimate the effects of linkage strength but not of matching: at the survey date, unemployed workers cannot be in a matched (or mismatched) occupation. We estimate both within-country regressions (Equation 4) and between-country regressions (Equation 5):

$$
\begin{gathered}
y_{i}=\alpha+\beta L_{i g}+\Sigma \gamma_{l} S_{i l}+\delta X_{i}+\varepsilon_{i} \\
y_{i}=\alpha+\beta_{1} L_{i g m}+\delta X_{i}+\zeta_{j} F_{i j}+\Sigma \gamma_{l} S_{i l}+\varphi C_{i}+\varepsilon_{i}
\end{gathered}
$$

where $y_{i}$ is a binary variable indicating whether individual $i$ was employed or unemployed as of the survey date. Our between-country analyses take the same form as those discussed above. We use linear probability fixed-effects models due to the technical limitation stemming from the fact that workers in the same educational category, $F$, will generally have different probability weights.

\section{Results}

\section{Descriptive Results}

We start by outlining how strongly detailed educational credentials are linked to occupational structure. Figure 1 presents the linkage scores for the educational levels and fields of study for France, Germany, and the United States. Keeping in mind the very low linkage strength for the United States at the secondary level (linkage strength .09), we see very clear differences between the three countries in linkage strength at the (upper-)secondary level (see Table 1), which is not surprising given that the largest differences between the skill-formation systems play out at the (upper-)secondary level. Differences among the three countries are smaller when we focus on tertiary education, although - as at the secondary level - Germany has the strongest linkage. Note, however, that while all three countries have tertiary degrees that have a more vocational nature (i.e., professional qualifications), a large share of educational programs at the tertiary level have a relatively weak link to the labor market compared to the average scores for tertiary as a whole (see Figure 1). 
Figure 1: Linkage strength in the United States, France, and Germany

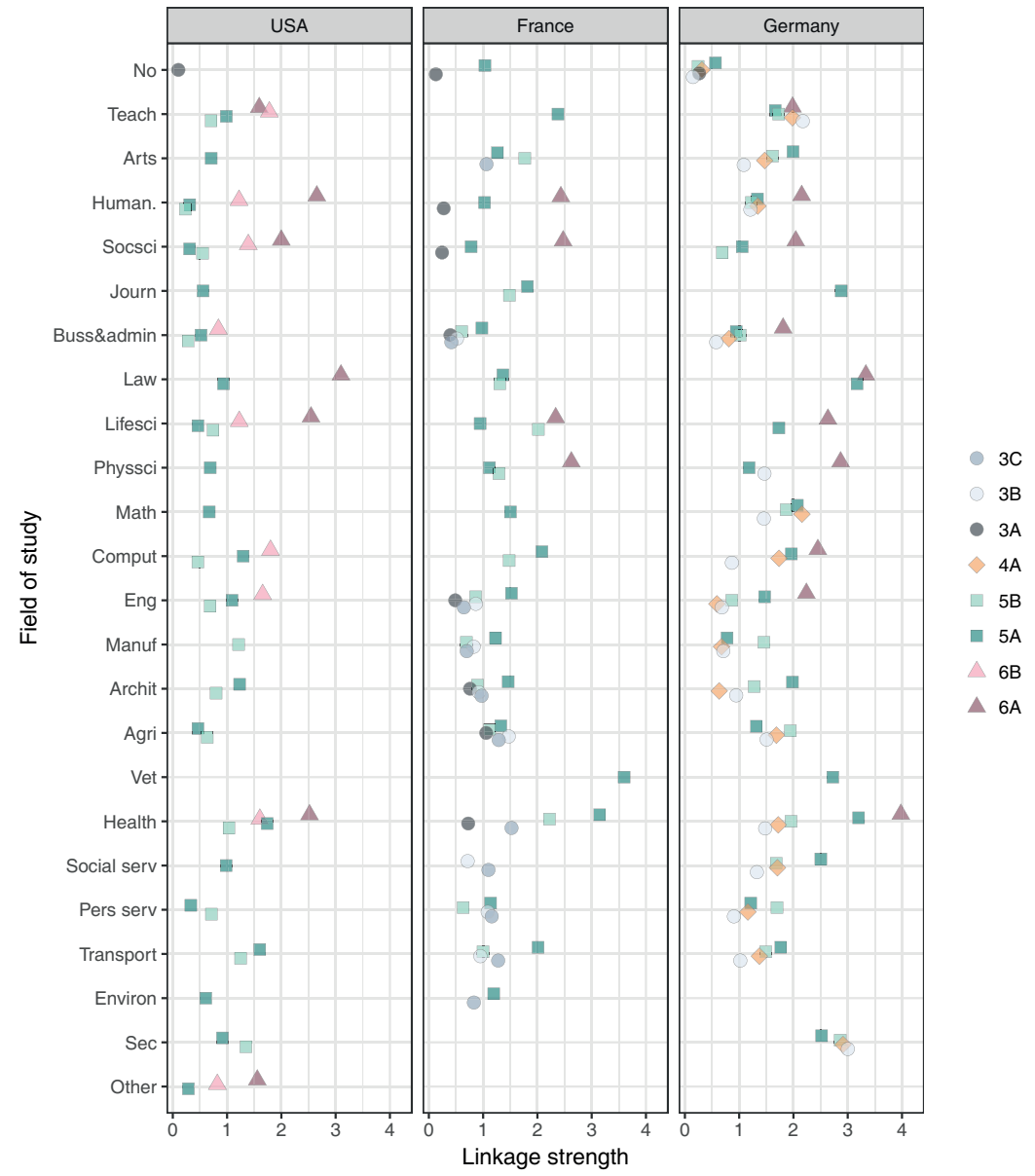

Source: Enquete Emploi 2005-2011 for France, Microcensus 2006 for Germany, and the SIPP 2004, SIPP 2008, and the American Community Survey 2009 for the United States.

Figure 1 clearly shows that linkage strength varies significantly within and between countries, with variation generally larger at the upper-tertiary level. The field of health (especially at university level, 5A or 6) is strongly linked to the labor market, meaning graduates from this field work in a restricted set of occupations. Other strongly linked fields are law (in the United States only at the postgraduate level), veterinary, and teaching. Fields that link poorly to specific occupations include personal services, business administration, and the arts. Overall linkage is weakest in the United States and strongest in Germany; France lies in between.

Table 1 shows the proportion of workers in the two strongest matching occupations is higher for workers with tertiary than with upper-secondary education and generally greater in Germany than in France or the United States. Germany and France are more similar in the proportion of upper-secondary workers in the two best-matching (by our statistical criterion) occupations than they are in linkage strength. Note, however, that linkage strength measures the extent of clustering of workers with a given educational credential across the entire set of occupations (not just the two best- 
matching occupations) so these measures are not in conflict. One possible interpretation of these comparisons is that Germany has fewer upper-secondary workers who are badly matched than does France. When we use the measure with the four strongest matching occupations, we indeed find that in upper-secondary education, Germany has a higher proportion of matched workers (.40) compared to France (.34). ${ }^{12}$ As we show in the online supplement, our findings remain the same when we define "making the match" by looking at the top four (or three) occupations.

\section{Analyses of Earnings: Within-Country Results}

Table 2 presents results using the within-country design where the linkage strength of educational credentials is only included as a main effect. For France and Germany, we estimate separate regressions for upper-secondary (Models 1 and 3) and tertiary (Models 2 and 4) education. For the United States, we estimate two models, one including lower tertiary and upper tertiary up to four-year degrees (Model 5, fouryear) and a model that includes all tertiary degrees including graduate degrees (Model $6,4+$ years). We do this because the United States is distinctive in having so many tertiary students with graduate degrees. Although the models only show the effects for linkage strength and educational level, the regressions include control variables for age, age squared, and gender.

Not surprisingly, level of education is strongly associated with earnings. In France we find that upper-secondary general graduates (3A) earn generally higher earnings than their vocationally trained counterparts $(3 \mathrm{~B}, 3 \mathrm{C})$. The opposite is true for Germany, where the wages of vocational degree-holders $(3 \mathrm{~B}, 4)$ are slightly higher. For all countries we find that graduates in higher tertiary education $(5 \mathrm{~A})$ have significantly higher earnings than those with a lower tertiary degree (5B). In France this difference is about 18 percent $(\exp (.164))$, in Germany 31 percent $(\exp (.271))$, and in the United States it is 47 percent $(\exp (.383))$.

Is strong linkage between education and occupation associated with higher earnings? Table 2 shows the answer to this question depends on the level of education. The perhaps surprising answer is that linkage strength is negatively related to gross monthly earnings in France at the secondary level, although the effect size is small. An increase of .33 in linkage strength (a standard deviation increase across fields at the secondary-education level) is associated with a 1 percent decrease in earnings in France. One explanation for this might be that French graduates with a secondary degree from more weakly linked fields of study are upwardly mobile in the labor market, resulting in slightly higher wages, relatively speaking. Note, however, that although statistically significant, the effect size is very small. In Germany we find a very small positive association between linkage strength and earnings at the upper-secondary level (Model 3), but this effect is too small to reach conventional levels of statistical significance.

\footnotetext{
${ }^{12}$ The proportion of workers who are in the two best-matching occupations in Germany is lower than the 50 percent of workers who reported in the early waves of the SOEP that they are working in the occupation they were trained for (Witte and Kalleberg 1995). TThere are several possible reasons for this, including that Witte and Kalleberg only measured fit for recent graduates (linkage strength declines over the work career even in Germany (DiPrete et al. 2017)), that the Witte and Kalleberg measure is only for workers who completed some form of post-secondary education (linkage strength is higher for post-secondary than for upper-secondary educated workers), and that Witte and Kalleberg excluded workers who were subsequently unemployed or did not respond to the question (the omitted workers could have a poorer fit than the included workers).
} 
Table 2: Effects of Linkage on Gross Monthly Earnings (within country, between field)

\begin{tabular}{|c|c|c|c|c|c|c|}
\hline & \multicolumn{2}{|c|}{ France } & \multicolumn{2}{|c|}{ Germany } & \multicolumn{2}{|c|}{ US } \\
\hline & $\begin{array}{c}(1) \\
\text { Secondary }\end{array}$ & $\begin{array}{c}(2) \\
\text { Tertiary }\end{array}$ & $\begin{array}{c}(3) \\
\text { Secondary }\end{array}$ & $\begin{array}{c}(4) \\
\text { Tertiary }\end{array}$ & $\begin{array}{c}(5) \\
4 \text { year }\end{array}$ & $\begin{array}{c}(6) \\
4+\text { years }\end{array}$ \\
\hline Linkage strength & $\begin{array}{c}-0.030^{* *} \\
(-5.07)\end{array}$ & $\begin{array}{l}0.076^{* *} \\
(21.03)\end{array}$ & $\begin{array}{l}0.011 \\
(2.56)\end{array}$ & $\begin{array}{l}-0.008 \\
(-1.54)\end{array}$ & $\begin{array}{l}0.062^{* *} \\
(11.30)\end{array}$ & $\begin{array}{c}0.048^{* *} \\
(6.24)\end{array}$ \\
\hline \multicolumn{7}{|l|}{ Level of Education } \\
\hline $3 \mathrm{C}$ & $\begin{array}{c}-0.114^{* *} \\
(-21.60)\end{array}$ & & & & & \\
\hline \multicolumn{7}{|l|}{ 3B (reference) } \\
\hline $3 \mathrm{~A}$ & $\begin{array}{c}0.038^{* *} \\
(5.85)\end{array}$ & & $\begin{array}{c}-0.048^{*} \\
(-2.95)\end{array}$ & & & \\
\hline 4 & & & $\begin{array}{c}0.206^{* *} \\
(37.90)\end{array}$ & & & \\
\hline $5 \mathrm{~B}$ & & $\begin{array}{c}-0.164^{* *} \\
(-36.94)\end{array}$ & & $\begin{array}{c}-0.271^{* *} \\
(-46.52)\end{array}$ & $\begin{array}{c}-0.383^{* *} \\
(-57.88)\end{array}$ & $\begin{array}{c}-0.384^{* *} \\
(-56.96)\end{array}$ \\
\hline \multicolumn{7}{|l|}{ 5A (reference) } \\
\hline $6 \mathrm{~B}$ & & & & & & $\begin{array}{l}0.144^{* *} \\
(12.62)\end{array}$ \\
\hline $6 \mathrm{~A}$ & & $\begin{array}{l}0.011 \\
(0.65)\end{array}$ & & $\begin{array}{c}0.286^{* *} \\
(19.18)\end{array}$ & & $\begin{array}{l}0.355^{* *} \\
(15.11)\end{array}$ \\
\hline Constant & $\begin{array}{c}6.543^{* *} \\
(284.33)\end{array}$ & $\begin{array}{c}6.318^{* *} \\
(191.48)\end{array}$ & $\begin{array}{c}6.619^{* *} \\
(269.63)\end{array}$ & $\begin{array}{c}6.974^{* *} \\
(140.58)\end{array}$ & $\begin{array}{c}6.341^{* *} \\
(202.64)\end{array}$ & $\begin{array}{c}6.447^{* *} \\
(150.33)\end{array}$ \\
\hline Controls & Yes & Yes & Yes & Yes & Yes & Yes \\
\hline Observations & 60503 & 41789 & 74213 & 33812 & 217237 & 223517 \\
\hline$R^{2}$ & 0.24 & 0.33 & 0.18 & 0.24 & 0.17 & 0.21 \\
\hline
\end{tabular}

Note: Control variables included in the model are age, age $^{2}$, and gender. $t$-statistics are in parentheses.

${ }^{*} p<0.01,{ }^{* *} p<0.001$, two-tailed tests. 
At the tertiary level, in contrast, stronger linkage has a positive association with earnings in two out of three countries. In France the effect is .076 log points, or an increase of about 5 percent for each standard deviation increase in linkage strength. In Germany we find no effect, but in the United States the effects are more comparable in size to those in France: .062 for four-year degrees and .048 for four+ years degrees, equal to about a 3 to 4 percent earnings gain for each standard deviation increase in linkage strength.

Table 3: Effects of Linkage and Match on Gross Monthly Earnings (within country, between field)

\begin{tabular}{|c|c|c|c|c|c|c|}
\hline & \multicolumn{2}{|c|}{ France } & \multicolumn{2}{|c|}{ Germany } & \multicolumn{2}{|c|}{ US } \\
\hline & (1) & $(2)$ & $(3)$ & $(4)$ & (5) & (6) \\
\hline & Secondary & Tertiary & Secondary & Tertiary & 4 year & $4+$ years \\
\hline Linkage strength & $\begin{array}{c}-0.033^{* *} \\
(-4.44)\end{array}$ & $\begin{array}{c}0.026^{* *} \\
(4.80)\end{array}$ & $\begin{array}{c}-0.084^{* *} \\
(-12.73)\end{array}$ & $\begin{array}{c}-0.067^{* *} \\
(-9.40)\end{array}$ & $\begin{array}{c}-0.023^{*} \\
(-2.90)\end{array}$ & $\begin{array}{l}-0.016 \\
(-1.58)\end{array}$ \\
\hline In matched occ. & $\begin{array}{l}0.008 \\
(1.00)\end{array}$ & $\begin{array}{c}0.039^{* *} \\
(3.62)\end{array}$ & $\begin{array}{c}-0.151^{* *} \\
(-16.35)\end{array}$ & $\begin{array}{c}-0.062^{* *} \\
(-4.13)\end{array}$ & $\begin{array}{l}-0.016 \\
(-1.61)\end{array}$ & $\begin{array}{l}0.004 \\
(0.28)\end{array}$ \\
\hline Linkage $*$ matched & $\begin{array}{l}0.002 \\
(0.15)\end{array}$ & $\begin{array}{c}0.053^{* *} \\
(7.21)\end{array}$ & $\begin{array}{l}0.191^{* *} \\
(21.45)\end{array}$ & $\begin{array}{c}0.083^{* *} \\
(9.33)\end{array}$ & $\begin{array}{l}0.151^{* *} \\
(13.76)\end{array}$ & $\begin{array}{c}0.082^{* *} \\
(5.79)\end{array}$ \\
\hline Controls & Yes & Yes & Yes & Yes & Yes & Yes \\
\hline Observations & 60503 & 41789 & 74213 & 33812 & 217237 & 223517 \\
\hline$R^{2}$ & 0.24 & 0.34 & 0.19 & 0.24 & 0.18 & 0.21 \\
\hline
\end{tabular}

Note: Models 1 and 3 (secondary) include 3C to 4A. Models 2, 4, and 6 (tertiary) include 5B to 6B.

Model 5 includes 5B and 5A (four-year). Control variables included in the models are gender, educational level, and linear and quadratic terms in age. $t$-statistics are in parentheses.

${ }^{*} p<0.01,{ }^{* *} p<0.001$, two-tailed tests.

If we instead conceptualize linkage effects as involving both structural characteristics and the quality of individual matches, the picture changes considerably (see Table 3). The results in Table 2 imply that upper-secondary-educated workers in Germany obtain a slight earnings premium if they were trained in a field that links relatively strongly to the occupational structure of the labor market. Table 3 qualifies this result: being educated in a strongly linked educational field produces an expected positive outcome only if the worker is in a matched occupation.

Figure 2 illustrates the different implications of linkage strength for workers who are in matched occupations and those who are not by showing the earnings contrasts between those who make the match and those who do not for different levels of linkage strength. For French graduates with an upper-secondary degree (top panel A), there is no wage difference between workers who make or do not make the match, and this null effect does not vary with the linkage strength of a degree. In Germany, in contrast, making a match is more remunerative when an upper-secondary degree is more strongly linked to the labor market. 
Figure 2: Earnings contrasts between workers in matched versus non-matched occupations

(a) Secondary degrees
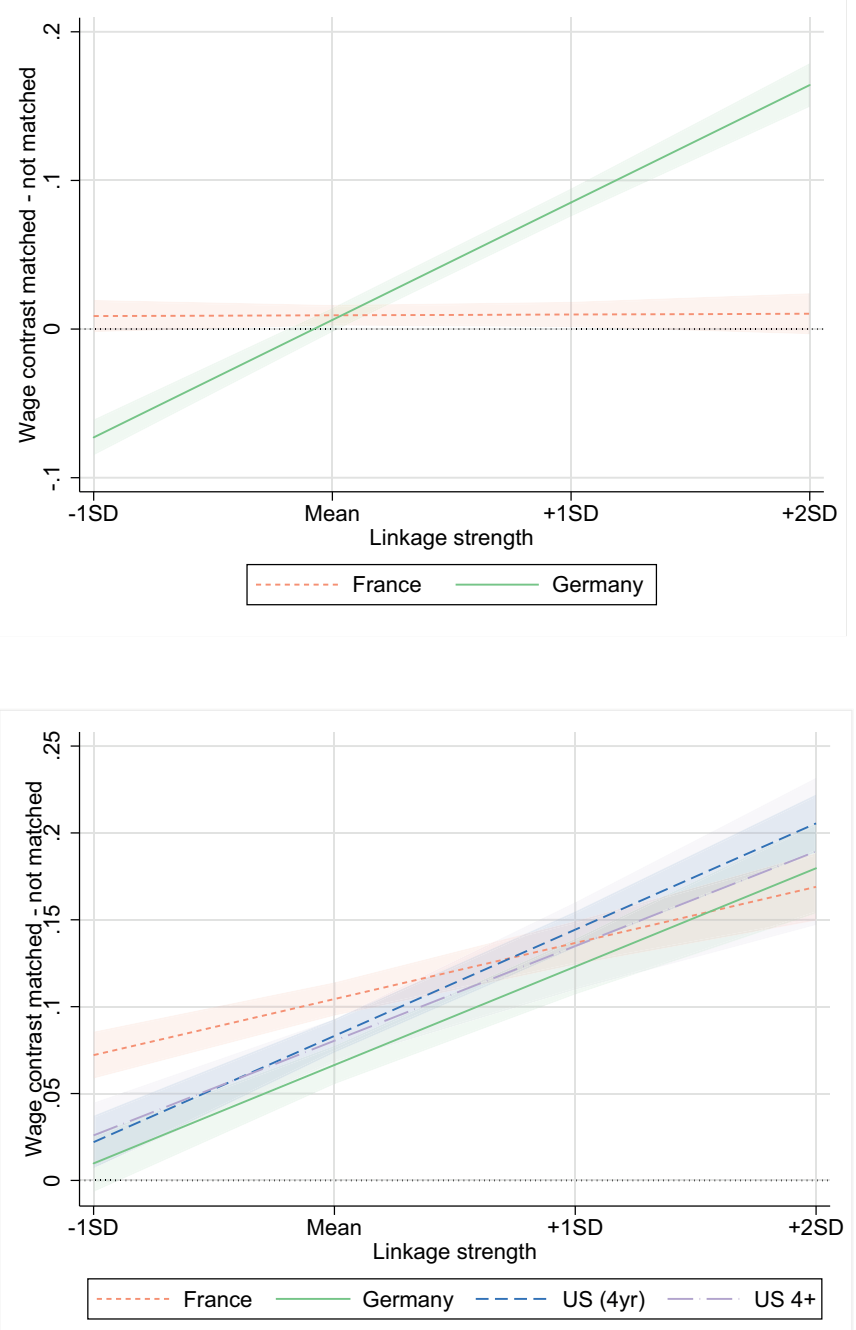

(b) Tertiary degrees

Note: Earnings contrasts estimated from the regression models in Table 3.

German graduates with an upper-secondary degree from a field with strong labor market linkage (1SD above the mean) earn about 9 percent more when they make the match compared to when they do not. To give an example, this model predicts that graduates with an upper-secondary degree in "security" earn higher earnings if they end up working in security ("protective service workers" ISCO-88 category 516, or "police" ISCO-88 category 345) than in another occupation. This gap is particularly large because the field of security generally channels graduates to a small set of occupations (it has a high linkage strength).

The advantages to being in a matched occupation are qualitatively similar in the three countries for workers with tertiary-level education. In France, a tertiary-educated 
worker in a matched occupation gains approximately a 15 percent earnings advantage over an unmatched worker if her educational credential is strongly linked $(+1 \mathrm{SD})$ to the labor market. For Germany and the United States, the comparable advantage to being in a matched occupation is similar, irrespective of whether we focus on four-year degrees or all tertiary degrees (four-year and higher).

Linkage is clearly an important structural feature of the labor market, and it generally accentuates the earnings effects of working in an (un)matched occupation. This conclusion holds for the upper-secondary level in Germany and at tertiary education for all three countries: being in a matched occupation generally produces a larger earnings advantage when workers also possess a credential that links strongly to the labor market. In contrast, being in an unmatched occupation generally produces a larger earnings disadvantage when workers possess a more strongly linking credential after controlling for age, gender, and specific educational level. The within-country results thus confirm Hypothesis 3.

The results from Figure 2 also provide support for our hypothesis that a country's skill-formation system plays an important role. Secondary graduates in Germany are educated in a highly occupation-specific dual system, and workers who make the match gain a much larger earnings premium than do secondary-education graduates in France. Alternatively, one could argue that the penalty to not making a match is very large in German upper-secondary education. For graduates from a strongly linking educational program, the predicted earnings penalty for not making the match is about 10 to 20 percent. In France, wage differences between matched and unmatched workers with upper-secondary degrees are nonexistent. The pattern of results presented in Figure 2 supports Hypothesis 4.

\section{Analyses of Earnings: Between-Country Results}

As discussed earlier, a potential problem with the within-country models is that they do not control for other aspects of educational credentials that may both affect earnings and be associated with linkage strength. We therefore estimate Equation 3 to assess whether linkage strength and being in a matched occupation confer earnings advantages when comparing workers in the same broad educational level and field, but across different countries.

Table 4 presents results of these regressions for four different combinations of countries and educational levels: (1) France-Germany (secondary only), (2) France-Germany (tertiary only), (3) France-Germany-United States (tertiary up to four-year degrees only), and (4) France-Germany-United States (tertiary up to $4+$ years degrees). In these regressions, where we compare workers with the same broad educational level and the same field of study, we find a similar story to that told by the within-country regressions, although there are some exceptions.

In line with the within-country results, for the French-German comparison in secondary education (Table 4, Model 1), we find that everyone benefits from being in a strongly linked educational program (.085), but this effect is stronger for workers who employed in a matched occupation. For tertiary education we find the same: in countries where the same educational credential is more strongly linked to the occupational structure of the labor market, the earnings of those workers tend to be higher, and this effect is stronger for workers in matched occupations. Mismatched workers suffer larger penalties when they have educational credentials that link strongly to the labor 
Table 4: Effects of Linkage and Match on Gross Monthly Earnings (within level-field, between country)

\begin{tabular}{lcccc}
\hline & $(1)$ & $(2)$ & $(3)$ & $(4)$ \\
& Fr-D, Secon. & Fr-D, Tert. & F-D-US, Tert. 4yr & F-D-US, Tert. 4+ \\
\hline Linkage strength & $0.085^{* *}$ & $0.059^{* *}$ & 0.000 & 0.015 \\
& $(5.95)$ & $(6.26)$ & $(0.03)$ & $(1.47)$ \\
In matched occ. & $-0.026^{* *}$ & $0.026^{*}$ & $0.022^{*}$ & $0.033^{* *}$ \\
& $(-3.59)$ & $(2.62)$ & $(3.26)$ & $(3.62)$ \\
Linkage ${ }^{*}$ matched & $0.053^{* *}$ & $0.032^{* *}$ & $0.054^{* *}$ & $0.035^{* *}$ \\
& $(6.54)$ & $(4.87)$ & $(10.72)$ & $(4.17)$ \\
Controls & Yes & Yes & Yes & Yes \\
\hline Observations & 134716 & 75601 & 290521 & 299118 \\
$R^{2}$ & 0.36 & 0.46 & 0.29 & 0.32 \\
\hline Note: Control variables included in the model are age, age ${ }^{2}$, gender, educational level, and country. \\
$t$-statistics are in parentheses. \\
$*{ }^{*} p<0.01,{ }^{* *} p<0.001$, two-tailed tests.
\end{tabular}

market. This finding is consistent across the three different comparisons of tertiary educational degrees (Table 4, Models 2, 3, and 4).

Across the different analyses we find that linkage strength in one form or another provides earnings benefits. Yet we also see variation in whether the benefit is due to the individual worker's position in a particular, matched occupation, or the larger, national structure of linkage between field of study and occupation. These variations are, of course, related: when linkage strength is high, then a higher proportion of workers with that educational credential will be in occupations that match to that field of study. 13

In the next set of analyses, we estimate these results by gender and by "younger" and "older" workers to determine whether the impact of linkage varies across the work career. We analyze age groups separately to evaluate claims that there are long-term negative consequences of being educated in a "rigid" (vocational) as opposed to a "flexible" (general) program (Hanushek et al. 2017; Forster et al. 2016).

The results are presented in plots for the subgroups and are combined in Figure 3. As noted earlier, linkage strength varies more at the tertiary than at the secondary level. ${ }^{14}$ Given the variation in linkage scores at the different levels (see also Figure 1), we express their ranges in the means and standard deviations specific to that sample. As Figure 3 shows, linkage strength (x-axis) matters for predicted log gross monthly earnings (y-axis), but it does so differently for workers in matched (solid line) versus not matched (dashed line) occupations.

\footnotetext{
${ }^{13}$ Across the three countries, the Pearson $\mathrm{R}$ correlation between being in a matched occupation and linkage strength is .28.

${ }^{14}$ For the French-German comparison of secondary-school-educated workers, the mean local linkage score is .76 with a standard deviation of .40. At the tertiary level, the mean local linkage score for the combined French-German data is 1.42 with a standard deviation of .67.. When the United States is included (using both four-year and higher-year tertiary degrees), the mean tertiary score is 1.12 with a standard deviation of .71.
} 
When comparing secondary-educated workers in the same educational category between France and Germany (Figure 3, column 1), we find that stronger linkage is generally associated with higher earnings for male workers in matched and unmatched occupations. The major difference between younger and older male workers is that younger workers gain a larger advantage from being in matched occupations relative to not being in matched occupations. Women with secondary degrees also have higher earnings when linkage is higher, and women seem to gain more from making a match (or, equivalently, to lose more when they work in occupations that are not matched to their educational credentials).

Figure 3: Marginal prediction for subgroups
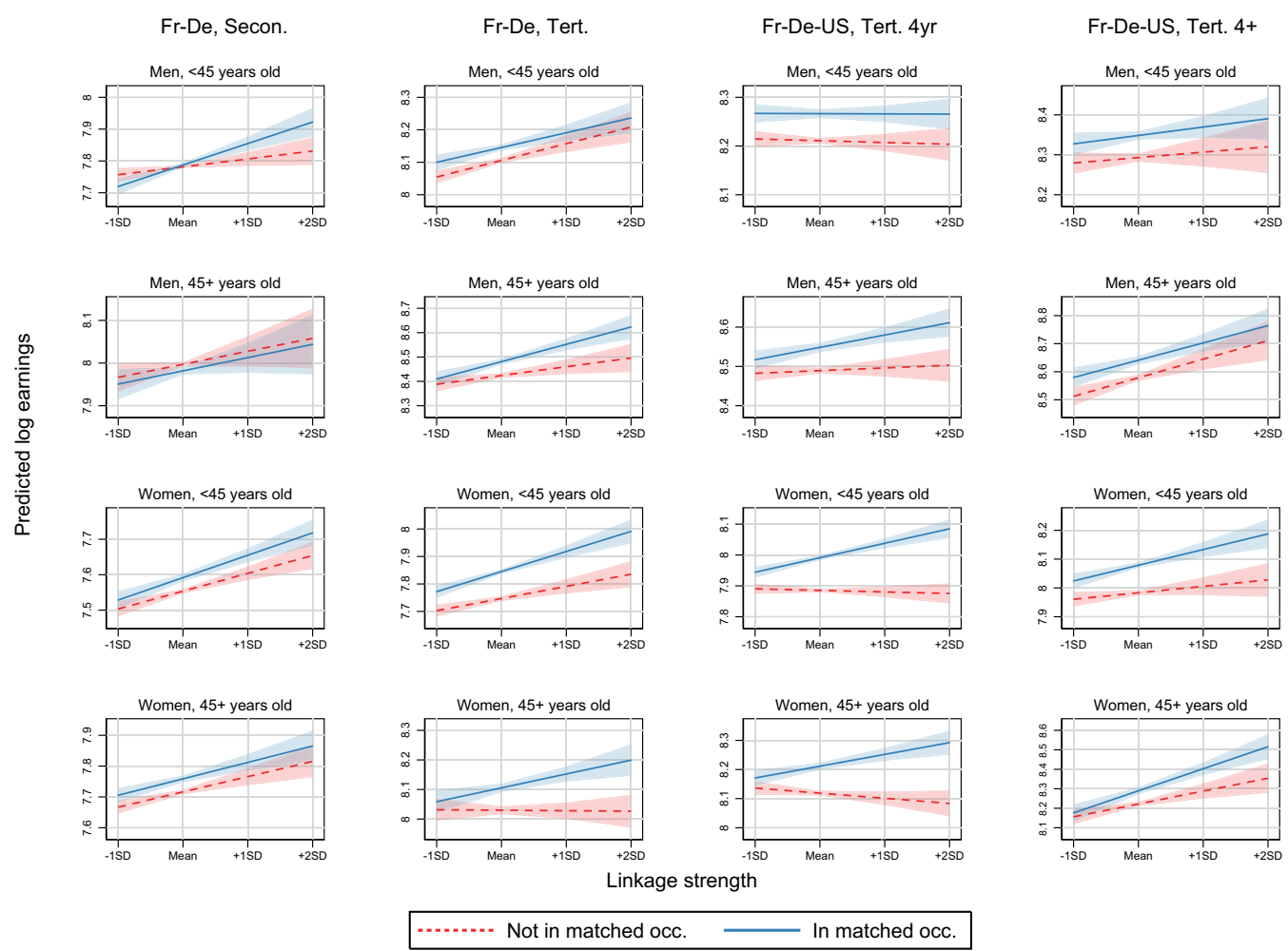

Note: The blue solid line is for workers who are in a matched occupation; the red dashed line is for workers who are not in a matched occupation.

Next, we turn to the case of tertiary-educated workers in France and Germany (second column in Figure 3). The pattern is quite similar for men and women and for younger and older workers: predicted earnings are higher when linkage is stronger, and workers in matched occupations particularly benefit from linkage strength. This pattern is more pronounced for women and least prominent for young (under 45 years) men. For older women the predicted wage gap between the matched and unmatched rises to about $.20 \mathrm{log}$ points $(+2 \mathrm{SD})$, whereas for younger men the effect of being in a matched occupation does not depend much on linkage strength.

When the United States is included with only up to four-year degrees (third column in Figure 3), the benefits of being in a matched occupation are evident for all age and 
gender groups, and the relative size of this benefit grows with linkage strength. In addition, when we include workers with graduate degrees (fourth column), the pattern is similar: predicted wages for the four groups are higher when workers are in matched occupations, and workers tend to achieve higher returns when an educational credential provides a clearer pathway to the labor market.

Overall, results from the between-country regression again confirm our hypotheses. We find an earnings premium for matched workers (Hypothesis 1), and earnings are positively associated with linkage strength (Hypothesis 2). Arguably, the more important result is the confirmation of Hypothesis 3: in general, the earnings gain from making a match is higher when the educational credential itself has strong linkage. These findings, in other words, imply that structural linkage and individual outcomes work together to structure earnings outcomes. To understand why matched workers obtain higher earnings in the labor market, it is crucial to take the linkage strength of an educational credential into account: graduates with strongly linking credentials benefit most from making the match, and they are penalized most when they do not make the match.

\section{Linkage Strength and Unemployment}

We found that linkage strength between educational outcomes and occupations provides earnings advantages (particularly for workers in matched occupations), but these results say little about workers who might drop out of the labor market all together. Several studies argue that a clear pathway between school and work protects against unemployment (Breen 2005; Shavit and Muller 2000). Others argue that the unemployment protection of linkage transforms into a liability as workers age (Hanushek et al. 2017).

Table 5: Effects of Linkage on Unemployment (within country, between field)

\begin{tabular}{|c|c|c|c|c|c|c|}
\hline & \multicolumn{2}{|c|}{ France } & \multicolumn{2}{|c|}{ Germany } & \multicolumn{2}{|c|}{ US } \\
\hline & (1) & $(2)$ & $(3)$ & $(4)$ & $(5)$ & (6) \\
\hline & Secondary & Tertiary & Secondary & Tertiary & 4 year & $4+$ years \\
\hline Linkage strength & $\begin{array}{c}-0.037^{* *} \\
(-10.30)\end{array}$ & $\begin{array}{c}-0.019^{* *} \\
(-13.09)\end{array}$ & $\begin{array}{l}0.000 \\
(0.24)\end{array}$ & $\begin{array}{l}0.000 \\
(0.28)\end{array}$ & $\begin{array}{c}-0.015^{* *} \\
(-11.98)\end{array}$ & $\begin{array}{c}-0.009^{* *} \\
(-6.48)\end{array}$ \\
\hline Controls & Yes & Yes & Yes & Yes & Yes & Yes \\
\hline Observations & 91869 & 60524 & 135110 & 57949 & 273303 & 280458 \\
\hline$R^{2}$ & 0.03 & 0.01 & 0.01 & 0.01 & 0.00 & 0.01 \\
\hline
\end{tabular}

Note: Models 1 and 3 (secondary) include 3C to 4A. Models 2, 4, and 6 (tertiary) include 5B to 6B.

Model 5 includes 5B and 5A (four-year). Control variables included in the models are gender, educational level, and linear and quadratic terms in age. $t$-statistics are in parentheses.

${ }^{*} p<0.01,{ }^{* *} p<0.001$, two-tailed tests.

To evaluate these assertions, we estimate similar models as above but use unemployment instead of earnings as the dependent variable. Our sample now includes respondents who are currently either unemployed or full- or part-time employed. ${ }^{15}$ We

\footnotetext{
${ }^{15}$ The sample size grows slightly because we recover cases for employed workers with missing earnings
} 
do not include terms involving whether the respondent is in a matched occupation, because unemployed individuals do not have a current occupation. We analyze crosssectional data, so we cannot assess the effect of working in a matched occupation on the risk of subsequent unemployment. Instead, we address whether the linkage strength of an educational credential is related to the probability of unemployment. ${ }^{16}$ Table 5 reports the results of the within-country analysis; Table 6 reports coefficient estimates from the between-country fixed-effects models.

In the within-country analyses, we find no evidence that greater linkage strength increases the probability of being unemployed. In France, in contrast, we find a significant negative effect of linkage strength on unemployment at the secondary $(3.7$ percentage points per unit of linkage strength) and tertiary (1.9 percentage points) levels. In Germany, there is no effect in either a positive or negative direction. In the United States, as in France, there is a significant negative association between linkage strength and the probability of unemployment for tertiary degree-holders of about a percentage point decrease in unemployment (depending on which group of tertiary degrees is considered) for each unit increment in linkage strength. Graduating from a field strongly linked to the labor market is associated with lower unemployment risks. However, the absence of an effect in Germany might indicate that a clear link from school to work matters most in the countries where such a link is structurally rarer.

Table 6: Effects of Linkage on Unemployment (within level-field, between country)

\begin{tabular}{lcccc}
\hline & $(1)$ & $(2)$ & $(3)$ & $(4)$ \\
& Fr-D, Secon. & Fr-D, Tert. & F-D-US, Tert. 4yr & F-D-US, Tert. 4+ \\
\hline Local linkage & $-0.082^{* *}$ & $-0.014^{* *}$ & $-0.018^{* *}$ & -0.008 \\
& $(-14.15)$ & $(-4.19)$ & $(-6.66)$ & $(-1.69)$ \\
Controls & Yes & Yes & Yes & Yes \\
\hline Observations & 226979 & 118473 & 388145 & 398931 \\
$R^{2}$ & 0.02 & 0.01 & 0.01 & 0.01 \\
\hline Note: Control variables included are age, age ${ }^{2}$, sex, educational level, and country. \\
$t$ statistics are in parentheses. \\
${ }^{*} p<0.01,{ }^{* *} p<0.001$, two-tailed tests.
\end{tabular}

The estimates we obtain in the between-country fixed-effects models are similar to our results from the within-country models (see Table 6). In the between-country model estimates, we find that linkage strength is associated with a lower unemployment risk in all specifications. Figure 4 shows how predicted unemployment changes with linkage strength for the four educational level/country combinations shown in Table 6 . For reasons of interpretation, linkage strength is standardized, and the values on the $\mathrm{x}$-axis refer to standard deviation changes in linkage strength. Not surprisingly, the risk of unemployment is much higher for graduates with an upper-secondary degree (short-dashed line) than it is for graduates from tertiary education. Nevertheless, the pattern for all comparisons is similar: for graduates of educational programs with clear pathways to the labor market, on average the risk of unemployment is lower.

information (see Table A2).

${ }^{16}$ We estimate linear probability models because our sample weight variable necessarily varies within the educational categories that we control as fixed effects. 
Figure 4: Linkage strength and unemployment

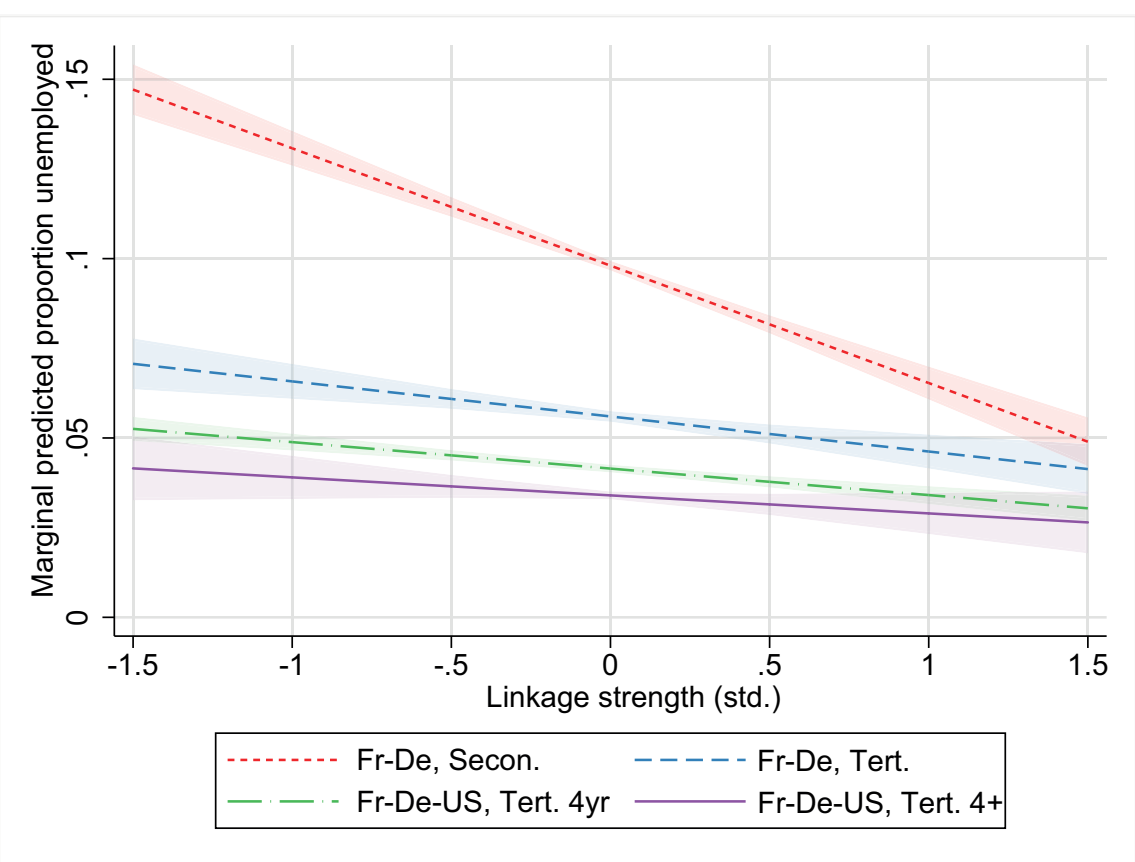

Note: Predicted marginal effects from Table 6. Shaded areas depict 95\% confidence intervals.

It is important to investigate whether the effects are similar for subgroups defined by age and gender, particularly given Hanushek et al. (2017) assertion that occupationspecific education harms the employment chances of older workers. Figure 5 plots the predicted effects of linkage strength on unemployment for age and gender subgroups. The predicted effect (for a one standard deviation increase in linkage strength) is negative for most subgroups. It does not differ significantly from zero for some workers in the tertiary comparisons, most prominently for younger men and older women.

In contrast to the earnings results, we find the strongest effects of linkage strength on unemployment for secondary-educated men, even though linkage strength is generally protective for female workers as well. Figure 5 also makes clear that there are no structural age differences in unemployment risk: older and younger workers alike benefit from a strongly linking educational degree at both secondary and tertiary levels of education. These findings argue against assertions that unemployment risk at older ages is heightened for individuals who earn "vocationally specific" educational credentials. Instead of a trade-off, we find reinforcing benefits; workers with educational credentials that link more strongly to the labor market have lower unemployment risk both early and later in their work careers, and, as we showed earlier, they generally achieve higher earnings as well. 
Figure 5: Linkage strength and unemployment across subgroups

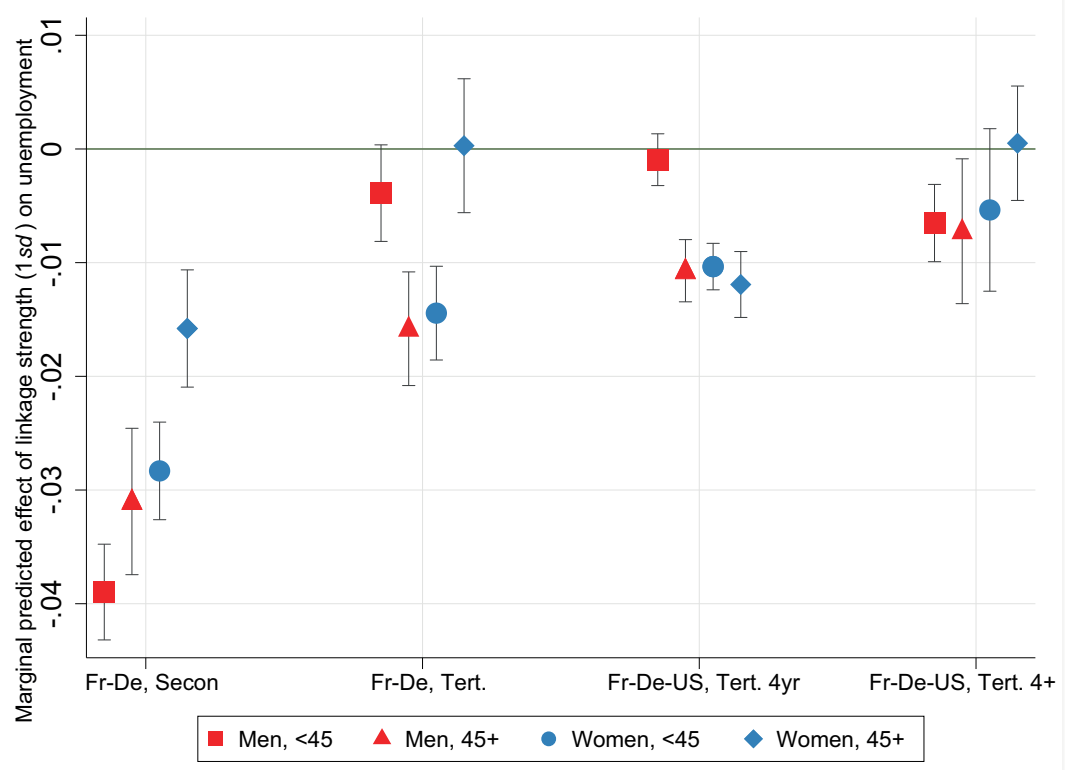

Note: Predicted marginal effects obtained from models for subgroups obtained from regressions similar to those in Table 4. The predicted effects are estimated for a one standard deviation increase in linkage strength on unemployment. Whiskers depict $95 \%$ confidence intervals.

\section{Discussion and Conclusions}

\section{Summary of Results}

How well are graduates from various educational qualifications matched to the occupational structure, and does a strong linkage between school and work generate higher earnings? We examined whether returns to education are affected by strong or weak linkage between specific educational levels and fields and the occupational structure in France, Germany, and the United States. We treated the structure of linkage as arising from both the institutional and the technical characters of education and the labor market. In contrast to earlier studies, we did not just define a strong or weak linkage at the level of a country's institutionalized skill-formation system, but also at the level of the educational credential. In doing so, we found that the granular structure of a country's training regime has important consequences for the employment and earnings distribution of its workers.

First, we find a (modest) positive association between the linkage strength of an educational program and the earnings of full-time workers who finish school in that program. On average, workers with tertiary educational credentials providing clear pathways to the labor market receive higher wages. Second, we find that graduates who end up working in a "matching" occupation do particularly well. Or, put differently, our models predict that workers who end up in an occupation that has no clear match with their educational credential obtain, on average, lower earnings. 
Our most important finding is that the extent to which making a match pays off depends on two contexts: (1) the linkage strength of educational credentials to the labor market and (2) the occupational specificity of the educational system. Our results indicate that strongly linking educational qualifications are associated with higher earnings, but especially so for workers who make the match. This finding is consistent across all graduates from tertiary education in the three countries.

We do find important cross-national differences at the upper-secondary (vocational) level. Graduates from the strongly occupation-specific German upper-secondary system receive a large earnings premium if they work in a matching job, and especially when their educational qualifications have clear occupational destinations. This pattern is absent for graduates from France's much more school-based upper-secondary system. An alternative, but equally plausible, way of looking at this is that German workers suffer large penalties when they end up in non-matching occupations. Overall, these results make clear that to understand the wage effects of school-to-work matches, it is important to consider the institutional context - at the educational credential level and the country level.

We find a negative association between linkage strength and the probability of unemployment. This relationship appears when we compare educational fields within France and the United States controlling for educational level; it again appears when we exploit variation across Germany, France, and the United States and across minor differences in educational level within the same educational field. Results from country fixed-effects models show that protection against unemployment from linkage strength is particularly strong for employed men with upper-secondary degrees. Contrary to assertions that strong pathways between education and occupations produce labor market rigidity and heightened unemployment risk, we find no evidence that stronger linkage produces greater chances of unemployment among older workers at either the secondary or the tertiary level. Instead, across age and gender groups, we find either no effect of linkage on unemployment risk or, more frequently, linkage actually has a protective effect against unemployment.

\section{Limitations and Suggestions for Future Research}

Our study has some limitations. We do not include enough countries in this analysis to determine whether the national-level institutional dimensions of educational systems and labor market institutions that are frequently used in larger- $\mathrm{N}$ comparative studies (e.g., the level of standardization or stratification of the educational system) affect earnings and unemployment risk when linkage strength and match quality are included in the model. A combined study of granular and macro-level structure would be an important step forward, although, at the same time, it is difficult to isolate the effects of broad institutional features on labor market outcomes in different countries from all the other differences that exist among countries. We offered two plausible mechanisms derived from human capital theory and social closure theory about why (mis)matching is consequential and why its effect varies with linkage structure, but our data did not allow us to test hypotheses about these mechanisms or whether social closure or human capital effects vary across countries. These limitations should be overcome in future work.

Even with these limitations, however, we believe our approach is powerful; it does a good job of identifying and isolating an important feature of educational and oc- 
cupational systems that can be measured and compared across countries. Based on the analyses reported here, the strength of linkage between educational outcomes and the occupational structure has important consequences for the life chances of individual workers and for the earnings distribution. Hence, it also matters centrally to the structure and extent of earnings inequality for a country as a whole.

\section{Policy and Theoretical Implications}

Our findings have important implications for policymakers. From a cross-national perspective, a strongly linked educational qualification improves workers' labor market prospects. Our results show that in this case, it is important to look at the overall skillformation system: a strong link from school to work seems to be particularly beneficial in contexts like Germany, where labor markets are structured in strong coordination with the educational systems. Although we do not directly measure "vocational" as opposed to "general" skills, many readers will translate linkage strength into vocational language, and indeed, this language is appropriate if it signals a greater tendency to be tracked into a relatively small set of occupations from a specific educational qualification. But strong linkage and the associated wage benefits are found across numerous fields at all levels, and across the traditional vocational-general classification.

Conditional on a given educational level, there is little evidence that students who learn skills that track into specific occupations suffer from their restricted employability across different types of occupations. The U.S. experience is instructive in this respect: relative to other countries, the United States has very high rates of non-completion of tertiary education (Vossensteyn et al. 2015, Table 4.3; Snyder and Dillow 2016, 326.10).In the United States, the heterogeneity of the college quality distribution, the lack of clear pathways from many tertiary programs to well-paying jobs, and the high costs of education may be additional factors motivating students to stop their schooling before they intended. In each of these hypotheticals, the issue of student selection processes emerges. To take one notable example, students with the greatest academic skills and socioeconomic resources tend to "match" with the highest "quality" (i.e., most prestigious) colleges in the United States.

Following this example, the structure of linkage at the national level may be in part a function of the matching process between student attributes and college characteristics. As we discussed, we explored this hypothesis in sensitivity analyses across all three of our countries of interest (see the online supplement) and found that including students' academic ability in our models did not alter the results. Although the available data constrain our ability to make concrete claims regarding the broader impact of national variation in college quality distribution on the structure of linkages, we hypothesize that potential restrictions on employability resulting from students' accrual of occupation-specific skills will be felt most strongly among students attending colleges and universities with lower national recognition and prestige. We hope to explore this hypothesis in future work.

Skeptics of vocational educational systems often argue that workers in these systems risk being stuck with low mobility chances if technology or market change reduces demand for the occupations they trained for (Hanushek et al. 2017). Our results evince a different risk calculation: the fact of being trained in an educational field that strongly links to the occupational structure implicitly creates a system of winners and

losers. The winners are the graduates who actually secure work in the occupations most 
closely linked to their education. The economic losers are the mismatched workers in occupations that do not strongly link to their educational credentials. Thus, while our approach moves beyond claims that vocational and general education have different employment and wage profiles, a national system promoting occupationally specific education still draws support. Whether that will change in the roboticized labor market of the future we cannot foresee, but the empirical reality today is that occupationally specific training is still a valuable form of education in terms of employment and wages.

These results are useful for U.S. debates in which proponents of German-style vocational training systems (Hoffman 2011) stand in stark opposition to their antagonists who claim the provision of general skills is the way forward to prepare youth for the labor markets of tomorrow. The results will also hopefully reorient the literature to address the important question of whether the provision of general versus specific skills is a zero-sum proposition, which recent scholarship suggests it is not; in strongly vocationally oriented systems, there is no loss in general skills among graduates from intermediate degrees (Heisig and Solga 2015). Educational programs with strong linkage might also provide substantial general skills to their graduates, and, indeed, perhaps workers who graduate from strongly linked fields and who match well to their jobs are gaining an earnings advantage from a combination of strong general and strong specific skills. This conjecture merits serious investigation.

Even though the three countries under study differ in their overall levels of linkage between education and the occupational structure, the workers in these countries all experience a common process: mismatched workers do worse than well-matched workers. And being well- matched is typically more common in countries with strong linkage. It is important to note, however, that linkage strength varies widely across educational outcomes within countries. Even in the United States, with its relatively weak links between education and the occupational structure, some educational credentials link much more strongly than others.

We do not read our results to imply that all educational pathways should have strong linkage to the occupational structure. The goal of education is not solely to learn marketable skills, and many students who specialize in fields of study with low linkage do well in the labor market. Our results speak more pointedly to the structure of a country's educational system as a whole, as well as to the structure of a country's labor market. Linkage strength is not simply a product of the school curriculum: it also depends on the organization of the labor market.

As the comparative political economy literature has taught us, these two systems work together in the matching process, and hence they jointly influence the proportion of students holding any specific credential that matches well and the proportion that does not. These systems also work together in shaping the distribution of young people across the set of available educational credentials. In other words, both structure and composition play important roles in the overall linkage strength of a country's training regime, and both are potentially modifiable by social policy. Institutions change slowly, but change is possible, and beneficial change is more likely when its potential consequences are better understood. We see our article as contributing to that end.

By turning a more refined lens on the matching process that more or less strongly ties educational outcomes to occupations, we also highlight the potential value of the linkage approach for better understanding the structure of work careers, particularly in a comparative context. As a recent review of the literature on careers notes (Kalleberg 
and Mouw 2018, p. 284)2018: p. 284), occupations and organizations are "major work structures that shape the opportunities available in the labor market." This statement is certainly true, but it is also clearly the case that work careers are influenced by the structure of training and its implications for occupational placement and occupational mobility. The linkage approach ties occupations more rigorously to the training system. In doing so, it opens new avenues for studying how education, as a skill and as an institutionalized pathway to the labor market, affects the structure of career mobility as well as the structure of wages and unemployment. 


\section{References}

Aizenman, Joshua, Yothin Jinjarak, Nam Ngo, and Ilan Noy. 2017. "Vocational Education, Manufacturing, and Income Distribution: International Evidence and Case Studies." Technical report, National Bureau of Economic Research.

Allen, Jim, Petra Boezerooy, Egbert De Weert, and Rolf Van Den Velden. 2000. "Higher Education and Graduate Employment in the Netherlands." European journal of education 35:211-219.

Allmendinger, J. 1989. "Educational systems and labor market outcomes." European Sociological Review 5:231-250.

Becker, Gary S. 1962. "Investment in Human Capital: A Theoretical Analysis." The journal of political economy pp. 9-49.

Béduwé, Catherine and Jean-François Giret. 2011. "Mismatch of Vocational Graduates: What Penalty on French Labour Market?" Journal of vocational behavior 78:68-79.

BMBF. 2015. Report on Vocational Education and Training 2015. Bonn: Federal Ministry of Education and Research.

Bol, Thijs. 2014. "Economic Returns to Occupational Closure in the German Skilled Trades." Social Science Research 46:9-22.

Bol, Thijs and Herman G Van de Werfhorst. 2013. "Educational systems and the trade-off between labor market allocation and equality of educational opportunity." Comparative Education Review 57:285-308.

Bol, Thijs and Kim A. Weeden. 2015. "Occupational Closure and Wage Inequality in Germany and the United Kingdom." European Sociological Review 31:354-369.

Bourdieu, P. 1973. "Cultural reproduction and social reproduction." Knowledge, education and cultural change. London: Tavistock pp. 487-510.

Breen, Richard. 2005. "Explaining Cross-national Variation in Youth Unemployment: Market and Institutional Factors." European Sociological Review 21:125-134.

Collins, Randall. 1979. The credential society: An historical sociology of education and stratification. Academic Pr.

Croce, Giuseppe and Emanuela Ghignoni. 2012. "Demand and supply of skilled labour and overeducation in Europe: a country-level analysis." Comparative Economic Studies 54:413-439.

Di Stasio, Valentina. 2017. "Who Is Ahead in the Labor Queue? Institutions' and Employers' Perspective on Overeducation, Undereducation, and Horizontal Mismatches." Sociology of Education 90:109-126.

DiPrete, Thomas A., Thijs Bol, Christina Ciocca Eller, and Herman G. van de Werfhorst. 2017. "School-to-Work Linkages in the United States, Germany, and France." American Journal of Sociology 122:1869-1938. 
Domina, Thurston, Andrew Penner, and Emily Penner. 2017. "Categorical Inequality: Schools As Sorting Machines." Annual Review of Sociology .

Duncan, Greg J. and Saul D. Hoffman. 1981. "The Incidence and Wage Effects of Overeducation." Economics of Education Review 1:75-86.

Elliott, Jane and Vania Gerova. 2005. "Translation from US OCC 2000 to ISCO\# 88." Center for Longitudinal Studies .

Forster, Andrea, Thijs Bol, and Herman G. van de Werfhorst. 2016. "Vocational Education and Employment over the Life Cycle." Sociological Science 3:473-494.

Forster, Andrea G. and Thijs Bol. 2018. "Vocational Education and Employment over the Life Course Using a New Measure of Occupational Specificity." Social Science Research 70:176-197.

Freeman, Richard B. 1976. The Overeducated American. New York: Academic Press.

Gangl, Markus. 2004. "Institutions and the Structure of Labour Market Matching in the United States and West Germany." European Sociological Review 20:171-187.

Ghignoni, Emanuela and Alina Verashchagina. 2014. "Educational qualifications mismatch in Europe. Is it demand or supply driven?" Journal of Comparative Economics 42:670-692.

Goldin, Claudia D. and Lawrence F. Katz. 2009. The Race between Education and Technology. Harvard University Press.

Hall, Peter A. and David Soskice. 2001. Varieties of capitalism: The institutional foundations of comparative advantage. Oxford University Press.

Handel, Michael J. 2003. "Skills Mismatch in the Labor Market." Annual Review of Sociology 29:135-165.

Hanushek, Eric A., Guido Schwerdt, Ludger Woessmann, and Lei Zhang. 2017. "General Education, Vocational Education, and Labor-Market Outcomes over the Lifecycle." Journal of Human Resources 52:48-87.

Heisig, Jan Paul and Heike Solga. 2015. "Secondary Education Systems and the General Skills of Less- and Intermediate-Educated Adults A Comparison of 18 Countries." Sociology of Education 88:202-225.

Hoffman, Nancy. 2011. Schooling in the Workplace: How Six of the World's Best Vocational Education Systems Prepare Young People for Jobs and Life. Harvard Education Press.

Iversen, Torben and David Soskice. 2001. "An Asset Theory of Social Policy Preferences." The American Political Science Review 95:875-893.

Kalleberg, Arne L. and Ted Mouw. 2018. "Occupations, Organizations, and Intragenerational Career Mobility." Annual Review of Sociology 44. 
Katz-Gerro, Tally and Meir Yaish. 2003. "Higher Education: is more better? Gender Differences in Labour Market Returns to Tertiary Education in Israel." Oxford Review of Education 29:571-592.

Kerckhoff, Alan C. 1996. "Building conceptual and empirical bridges between studies of educational and labour force careers." In Generating social stratification: Toward a new research agenda, edited by Alan C. Kerckhoff, pp. 37-56.

Kirkeboen, Lars J., Edwin Leuven, and Magne Mogstad. 2016. "Field of study, earnings, and self-selection." The Quarterly Journal of Economics 131:1057-1111.

Kleiner, Morris M. 2006. Licensing Occupations: Ensuring Quality Or Restricting Competition? W.E. Upjohn Institute.

Korpi, Tomas and Michael Tåhlin. 2009. "Educational Mismatch, Wages, and Wage Growth: Overeducation in Sweden, 1974-2000." Labour Economics 16:183-193.

Labaree, David F. 1999. How to succeed in school without really learning: The credentials race in American education. Yale University Press.

Leuven, Edwin and Hessel Oosterbeek. 2011a. "Overeducation and Mismatch in the Labor Market." In Handbook of the Economics of Education, volume 4, pp. 283-326.

Leuven, Edwin and Hessel Oosterbeek. 2011b. "Overeducation and mismatch in the labor market." Technical Report 5523, Discussion paper series // Forschungsinstitut zur Zukunft der Arbeit.

Leuze, Kathrin. 2007. "What Makes for a Good Start? Consequences of OccupationSpecific Higher Education for Career Mobility: Germany and Great Britain Compared." International Journal of Sociology 37:29-53.

Levels, Mark, Rolf van der Velden, and Jim Allen. 2014. "Educational Mismatches and Skills: New Empirical Tests of Old Hypotheses." Oxford Economic Papers 66:959982.

Maurice, M., F. Sellier, and J. J Silvestre. 1986. The social foundations of industrial power: a comparison of France and Germany. The MIT Press.

McGuinness, Séamus. 2006. "Overeducation in the Labour Market." Journal of Economic Surveys 20:387-418.

Montt, Guillermo. 2015. "The causes and consequences of field-of-study mismatch." OECD Social, Employment and Migration Working Papers 167.

Mora, Ricardo and Javier Ruiz-Castillo. 2011. "Entropy-Based Segregation Indices." Sociological Methodology 41:159-194.

Mora, Ricardo and Javier Ruiz-Castillo Ucelay. 2009. "The statistical properties of the mutual information index of multigroup segregation." Documentos de trabajo. Economic series (Universidad Carlos III. Departamento de Economía) p. 1.

Müller, Walter and Markus Gangl. 2003. Transitions from Education to Work in Europe: The Integration of Youth into EU Labour Markets. Oxford University Press on Demand. 
Müller, W. and Y. Shavit. 1998. "The institutional embeddedness of the stratification process: A comparative study of qualifications and occupations in thirteen countries." From school to work: A comparative study of educational qualifications and occupational destinations pp. 1-48.

Nordin, Martin, Inga Persson, and Dan-Olof Rooth. 2010. "Education-occupation mismatch: Is there an income penalty?" Economics of education review 29:10471059.

Pedulla, David S. 2016. "Penalized or Protected? Gender and the Consequences of Nonstandard and Mismatched Employment Histories." American Sociological Review 81:262-289.

Protsch, Paula and Heike Solga. 2016. "The Social Stratification of the German VET System." Journal of Education and Work 29:637-661.

Redbird, Beth. 2017. "The New Closed Shop? The Economic and Structural Effects of Occupational Licensure." American Sociological Review 82:600-624.

Robst, John. 2007. "Education and job match: The relatedness of college major and work." Economics of Education Review 26:397-407.

Roksa, Josipa and Tania Levey. 2010. "What Can You Do with That Degree? College Major and Occupational Status of College Graduates over Time." Social Forces 89:389-415.

Shavit, Yossi and Walter Müller. 1998. From School to Work. A Comparative Study of Educational Qualifications and Occupational Destinations. Oxford: Oxford University Press.

Shavit, Yossi and Walter Muller. 2000. "Vocational Secondary Education." European Societies 2:29-50.

Snyder, Thomas D. and Sally A. Dillow. 2016. Digest of education statistics, 2014. Government Printing Office.

Thelen, Kathleen. 2004. How Institutions Evolve: The Political Economy of Skills in Germany, Britain, the United States, and Japan. Cambridge University Press.

Van de Werfhorst, Herman G. 2002. "Fields of Study, Acquired Skills and the Wage Benefit from a Matching Job." Acta Sociologica 45:286-303.

Van de Werfhorst, H. G. 2002. "Fields of study, acquired skills and the wage benefit from a matching job." Acta Sociologica 45:286-303.

Verhaest, Dieter and Rolf Van der Velden. 2013. "Cross-Country Differences in Graduate Overeducation." European Sociological Review 29:642-653.

Vogtenhuber, Stefan. 2014. "The Impact of within Country Heterogeneity in Vocational Specificity on Initial Job Matches and Job Status." Journal of Vocational Behavior 85:374-384. 
Vossensteyn, Johan J., Andrea Kottmann, Benjamin W. A. Jongbloed, Franciscus Kaiser, Leon Cremonini, Bjorn Stensaker, Elisabeth Hovdhaugen, and Sabine Wollscheid. 2015. Dropout and Completion in Higher Education in Europe: Main Report. European Union.

Weeden, Kim A. 2002. "Why Do Some Occupations Pay More than Others? Social Closure and Earnings Inequality in the United States." American Journal of Sociology 108:55-101.

Witte, James C. and Arne L. Kalleberg. 1995. "Matching Training and Jobs: The Fit between Vocational Education and Employment in the German Labour Market." European Sociological Review 11:293-317.

Wolbers, Maarten HJ. 2007. "Patterns of Labour Market Entry A Comparative Perspective on School-to-Work Transitions in 11 European Countries." Acta sociologica 50:189-210.

Wolbers, Maarten H. J. 2003. "Job Mismatches and their Labour-Market Effects among School-Leavers in Europe." European Sociological Review 19:249-266. 


\section{Appendices}

Please note that for the United States we only show the workers with a tertiary degree (ISCED 5 and higher), since this is the only group that is analyzed. This also explains the comparatively low unemployment rate in the US (0.03) compared to France and Germany.

Table A1: Descriptive statistics unemployment analyses

\begin{tabular}{|c|c|c|c|c|c|c|}
\hline & \multicolumn{2}{|c|}{ France } & \multicolumn{2}{|c|}{ Germany } & \multicolumn{2}{|c|}{ US } \\
\hline & Mean & SD & Mean & SD & Mean & $\mathrm{SD}$ \\
\hline Unemployed & 0.07 & & 0.09 & & 0.03 & \\
\hline Linkage strength & 0.91 & 0.60 & 1.07 & 0.63 & 0.92 & 0.65 \\
\hline Linkage strength (secondary) & 0.64 & 0.33 & 0.82 & 0.41 & - & \\
\hline Linkage strength (tertiary) & 1.25 & 0.61 & 1.55 & 0.68 & 0.94 & 0.66 \\
\hline Age & 38.84 & 10.97 & 42.25 & 10.74 & 42.60 & 11.26 \\
\hline Female & 0.48 & & 0.45 & & 0.50 & \\
\hline \multicolumn{7}{|l|}{ ISCED level } \\
\hline $3 \mathrm{C}$ & 0.37 & & - & & - & \\
\hline $3 \mathrm{~B}$ & 0.05 & & 0.60 & & - & \\
\hline $3 \mathrm{~A}$ & 0.17 & & 0.02 & & - & \\
\hline $4 \mathrm{~A}$ & - & & 0.08 & & - & \\
\hline $5 \mathrm{~B}$ & 0.17 & & 0.11 & & 0.21 & \\
\hline $5 \mathrm{~A}$ & 0.23 & & 0.18 & & 0.53 & \\
\hline $6 \mathrm{~B}$ & - & & - & & 0.19 & \\
\hline $6 \mathrm{~A}$ & 0.01 & & 0.01 & & 0.08 & \\
\hline \multicolumn{7}{|l|}{ Age category } \\
\hline$<45$ years old & 0.67 & & 0.57 & & 0.55 & \\
\hline $45=>$ years old & 0.33 & & 0.43 & & 0.45 & \\
\hline$N$ & 152 & 393 & 193 & 059 & 280 & 458 \\
\hline
\end{tabular}

Descriptive statistics are calculated using analytical weights. 
Table A2: Sample construction

\begin{tabular}{|c|c|c|c|c|c|c|}
\hline \multirow[b]{3}{*}{ Raw sample } & \multicolumn{2}{|c|}{ France } & \multicolumn{2}{|c|}{ Germany } & \multicolumn{2}{|c|}{ United States } \\
\hline & Cases lost & Cases left & Cases lost & Cases left & Cases lost & Cases left \\
\hline & & 391,572 & & 496,815 & & $3,116,082$ \\
\hline$+18-65$ year olds & 97,643 & 293,929 & 181,695 & 315,120 & $1,147,086$ & $1,968,996$ \\
\hline+ Out of education & 18,388 & 275,541 & 32,730 & 282,390 & 227,419 & $1,741,577$ \\
\hline + In occupation & 86,360 & 189,181 & 78,770 & 203,620 & 353,557 & $1,388,020$ \\
\hline+ US imputation of 5B-6B (SIPP) & - & - & - & - & 347,069 & $1,034,463$ \\
\hline+ No missing field of study information & 555 & 188,626 & & & 5,515 & $1,028,948$ \\
\hline+100 threshold & 1,683 & 186,943 & 1,397 & 202,223 & 824 & $1,028,124$ \\
\hline+ Education $>=$ ISCED 3 & 46,017 & 140,926 & 26,322 & 175,891 & 184,073 & 844,051 \\
\hline $\begin{array}{l}\text { +Removing ISCED } 3 \text { in the US since this } \\
\text { level includes no fields of study }\end{array}$ & - & - & - & - & 575,216 & 268,835 \\
\hline+ Only full-time & 24,864 & 116,062 & 41,701 & 134,190 & 36,618 & 232,217 \\
\hline+ Excluding self-employed & 13,052 & 103,010 & 17,664 & 116,526 & 8,587 & 223,630 \\
\hline + No missing earnings/controls & 718 & 102,292 & 8,501 & 108,025 & 113 & 223,517 \\
\hline
\end{tabular}

Note: See Data section for full description of US imputation. 
Table A3: ISCED 1997 Educational Levels

\begin{tabular}{|l|l|}
\hline ISCED Level & Description \\
\hline 0 & Pre-primary education \\
\hline 1 & Primary Education \\
\hline 2B & Lower secondary, direct access to 3C \\
\hline 2A & Lower secondary, access to 3A/3B \\
\hline 3C & Upper secondary, labor market access \\
\hline 3B & Upper secondary, access to 5B \\
\hline 3A & Upper secondary, access to 5A \\
\hline 4A & Preparation for entry to level 5 \\
\hline 5B & Lower tertiary education, occupation specific \\
\hline $5 \mathrm{~A}$ & Upper (4yr) tertiary education, preparation for a profession or advanced research \\
\hline 6 & Tertiary education, advanced (Germany \& France) \\
\hline $6 \mathrm{~B}$ & Tertiary education (U.S. Masters) \\
\hline $6 \mathrm{~A}$ & Tertiary education (U.S. Ph.D.) \\
\hline
\end{tabular}

Table A4: Fields of Study

\begin{tabular}{|l|l|}
\hline 0 General Programs & 52 Engineering/engineering trades \\
\hline 14 Teaching/education & 54 Manufacturing and processing \\
\hline 21 Arts & 58 Architecture and building \\
\hline 22 Humanities & 62 Agriculture, forestry and fishery \\
\hline 31 Social and behavioral science & 64 Veterinary \\
\hline 32 Journalism and information & 72 Health \\
\hline 34 Business and administration & 76 Social services \\
\hline 38 Law & 81 Personal services \\
\hline 42 Life sciences & 84 Transport services \\
\hline 44 Physical sciences & 85 Environmental protection \\
\hline 46 Mathematics and statistics & 86 Security services \\
\hline 48 Computing & 99 Unknown or unspecified \\
\hline
\end{tabular}

